\title{
Conspicuous consumption and household indebtedness
}

Article

Accepted Version

Lee, K. O. and Mori, M. (2021) Conspicuous consumption and household indebtedness. Real Estate Economics, 49 (52). pp. 557-586. ISSN 1540-6229 doi: https://doi.org/10.1111/15406229.12305 Available at https://centaur.reading.ac.uk/87143/

It is advisable to refer to the publisher's version if you intend to cite from the work. See Guidance on citing.

To link to this article DOI: http://dx.doi.org/10.1111/1540-6229.12305

Publisher: American Real Estate and Urban Economics Association

All outputs in CentAUR are protected by Intellectual Property Rights law, including copyright law. Copyright and IPR is retained by the creators or other copyright holders. Terms and conditions for use of this material are defined in the End User Agreement.

\section{www.reading.ac.uk/centaur}

\section{CentAUR}

Central Archive at the University of Reading

Reading's research outputs online 


\title{
Conspicuous Consumption and Household Indebtedness
}

\begin{abstract}
Using a novel, large dataset of consumer transactions in Singapore, we study how conspicuous consumption affects household indebtedness. The coexistence of private housing (condominiums) and subsidized public housing (HDB) allows us to identify conspicuous consumers. Conditional on income and other socioeconomic characteristics, those who choose to reside in condominiums - considered a status good in Singapore - are likely to be more conspicuous than their counterparts living in HDB units. We find that condominium residents spend considerably more (by 25\%) on conspicuous goods but not differently on inconspicuous goods. Compared with their matched HDB counterparts, these consumers with higher conspicuous motivation carry $7 \%$ more credit card debt and $108 \%$ more delinquent credit card debt. Our results suggest that status-seeking-induced conspicuous consumption is an important determinant of household indebtedness.
\end{abstract}

Keywords: conspicuous consumption, consumer indebtedness, credit card delinquency, residential circle

JEL codes: D12, D14, E21, R20 


\section{Introduction}

A significant increase in household debt has been reported in many developed countries despite these countries' economic strength. For example, the ratio of individual household debt to disposable income has grown from 20\% in 1945 to $134 \%$ in 2009 in the United States, and 2014 statistics show that the ratio remained high in many OECD countries (e.g., $113 \%$ in the United States, $164 \%$ in South Korea, 205\% in Australia, and 274\% in Netherlands). Along with the increase in real estate mortgage debt, one of the main drivers of the substantial growth of household debt was the increase in revolving debt, mainly credit card loans. In the United States, the share of revolving debt in total non-real estate consumer debt was as high as $41 \%$ in 1999 and remains at approximately 30\% (Federal Reserve). As of 2009, credit card debt outstanding was US\$870 billion and the delinquency rate on such debt reached $6.8 \%$ (Federal Reserve). In particular, household indebtedness remains high after the 2008 financial crisis and has been the focus of various macro policies (e.g., Di Maggio et al., 2016).

Although traditional approaches focus on liquidity constraints to explain household indebtedness, an increasing number of studies highlight social influences. For example, income ranking within a social network serves as a proxy for social status and plays an important role in influencing household behavior of overspending and debt accumulation (Vissing-Jorgensen, 2012; Georgarakos, Haliassos, and Pasini, 2014; Bricker, Ramcharan, and Krimmel, 2014). One potential mechanism to explain this behavior is conspicuous consumption, that refers to expenditures not made for consumers' own comfort or use but for the purpose of flaunting their wealth and income and, in turn, achieving greater social status (Veblen 1899). 
Although intuitively appealing, there is little evidence on the direct link between conspicuous consumption and household debt. Status-seeking incentives could create distortions in the intratemporal consumption decision by tilting disproportionately more consumption toward visible or conspicuous goods (Agarwal, Qian, and Zou, 2017; De Giorgi, Frederiksen, and Pistaferri, 2016). As such intratemporal substitution may not necessarily correspond to a spending level that leads to excess debt accumulation, however, it requires careful empirical investigation. Another empirical challenge lies in the difficulty of identifying conspicuous consumption motivation and accurately measuring (conspicuous) consumption.

In this study, we investigate the role of conspicuous consumption to understand household indebtedness. We measure status-seeking incentives by exploiting the unique dual feature of housing markets in Singapore that consist of public and private housing. Public housing called Housing Development Board (HDB ${ }^{1}$ ) provides the homes for $80 \%$ of the resident population with heavy government subsidies, while the private housing market is primarily comprised of condominiums (condos). Condos are viewed as an important status good in Singapore and aspired to more by those with stronger conspicuous desire. ${ }^{2}$ As geographic distinctions between HDBs and condos tend to be minimal, ${ }^{3}$ residential choices between HDBs and condos among individuals with similar income and demographics could potentially reveal the level of their conspicuous desire. The larger presence of conspicuous (middle-class) individuals in condos

\footnotetext{
${ }^{1}$ HDB also stands for Housing and Development Board, the statutory board of the Ministry of National Development that is responsible for public housing provision in Singapore.

${ }^{2}$ Singapore has often been viewed as materialistic and competitive society (NUS Institute of Policy Studies, 2018). It is revealed by 'Five Cs', namely condo, car, cash, credit card, and club memberships, which has been the common measure of success in Singapore. In this society where public housing is a dominant form of residence, condos have become a symbol of success that one could achieve only by paying a lot higher prices compared to public housing. ${ }^{3}$ Given that public housing in Singapore is the home for approximately $80 \%$ of the population, it is not associated with the same type of stigma typically prevalent in public or social housing in Anglo-American cities (Sin, 2002).
} 
leads to the hypothesis that perceived peer income is much higher and peer effects on conspicuous motivation are much stronger in condos than in HDBs.

We employ a unique dataset of a large representative sample of consumers that includes credit card and debit card transactions between April 2010 and March 2012 from a leading bank in Singapore with a more than $80 \%$ market share. Similar to the United States, debit and credit cards account for approximately 30\% of aggregate personal consumption (Agarwal and Qian, 2014). ${ }^{4}$ Therefore, our data provide fairly complete and accurate information about individuallevel non-housing consumption at high frequency. More importantly, merchant categories at the transaction level data allow us to obtain a finer measure of individual conspicuous consumption that identifies not only visibility and portability of the consumed goods but also the frequency and amount of consumption. We therefore believe that our analysis using this measure advances the existing research that relies on a specific spending item or a coarse classification scheme. Given the comprehensive nature of our consumption data, we are also able to examine whether conspicuous consumption crowds out inconspicuous consumption and analyze the direct link between consumption behavior and household indebtedness at the individual level.

We begin our analysis by identifying conspicuous consumption motivation based on individuals' residential circle choices between HDBs and condos. We analyze whether such motivation influences individuals' conspicuous consumption measured by the fraction of spending at conspicuous stores out of the total card spending as well as their indebtedness measured by credit

\footnotetext{
${ }^{4}$ The remaining $70 \%$ of consumption occurs through checks, direct transfers, and cash. Consumers with recurring payments, including mortgage, rent, and auto loan payments, typically use instruments such as checks and direct deposit.
} 
card debt and delinquency. We then examine the direct relationship between conspicuous consumption and credit card indebtedness and explore whether this relationship is contingent on individuals' conspicuous consumption motives. Taking advantage of the rich information at the individual level, we also investigate whether the relationships between residential circles, conspicuous consumption, and indebtedness are heterogeneous among individuals with different demographic characteristics.

Through an analysis of the matched sample based on income, housing wealth, and demographic characteristics, we find that people residing in condos spend more on conspicuous goods but less on other wellbeing goods compared with their matched counterparts in HDBs. Residing in condos increases conspicuous consumption by $25 \%$ relative to that of matched individuals in HDBs. In contrast, condo residents' spending on invisible or inconspicuous goods is not statistically significantly different from that of matched HDB residents. These findings support both our identification strategy and conspicuous consumption measure by confirming that condo residents are indeed more conspicuous and their consumption of expensive luxury goods is driven by conspicuous motivation.

Next, we document that individuals with stronger conspicuous motivation have more credit card debt and experience delinquency more often than their matched counterparts with weaker conspicuous motivation. Compared with their matched HDB counterparts, condo residents have $7 \%$ more credit card debt and $108 \%$ more delinquent credit card debt. This effect is significant both statistically and economically. Furthermore, higher conspicuous consumption results in more credit card debt and delinquency only for condo residents who have stronger conspicuous 
motivation. Among conspicuous individuals, younger, male, single individuals with low education level carried higher credit card debt. Finally, our results remain solid for alternative matching algorithms and additional robustness analyses.

This paper directly contributes to the literature on conspicuous consumption. The existing literature focuses on how conspicuous demand drives consumption behavior. Hopkins and Kornienko (2004) propose a theoretical model to suggest that people spend inefficiently high amounts on status goods and this tendency is amplified in a wealthier society. Similarly, Eaton and Eswaran (2009) demonstrate that conspicuous goods crowd out the consumption of wellbeing-inconspicuous goods as productivity increases. Drechsel-Grau and Schmid (2013) find that, in the U.S. context, envy motives are a more substantial driver of consumption behavior than habits. We add to the literature by documenting the debt consequences of conspicuous consumption. In measuring conspicuous consumption, most previous studies use relative income to capture the notion that it is motivated by comparisons of perceived socioeconomic standing or race among peers (Grinblatt, Keloharju, and Ikaheimo, 2008; Charles, Hurst, and Roussanov, 2009; Vissing-Jorgensen, 2012; Bricker, Ramcharan, and Krimmel, 2014; Georgarakos, Haliassos, and Pasini, 2014; Carr and Jayadev, 2015). Our study measures conspicuous motivation by exploring the individuals' revealed choices between residential circles that provide similar housing consumption services but differ in perceived status. By using administrative data on consumption and debt, we provide direct evidence of the associations between social influence, actual conspicuous consumption, and household indebtedness. 
This paper is also broadly related to the real estate literature as it connects the household's nonhousing consumption with their housing choice. One of the most popular topics in the literature is the effect of housing wealth gains on non-housing consumption. Vinson (2018) reports that while the net housing wealth effect is positive but modest, the collateral effect is significant for households with the higher borrowing constraint in the U.S.. On the other hand, Chen, Hardin, and $\mathrm{Hu}$ (2018) find that an increase in housing wealth has a much greater positive impact on consumption in the Chinese context compared to other developed countries. Others investigate how housing-related spending such as mortgage debts and mortgage payments influences nonhousing consumption and saving behaviors (Tunc and Yavas, 2016; Tunc and Yavas, 2017; Fan and Yavas, 2018; Güneş and Tunç, 2018). While we also look into non-housing consumption as an outcome of housing choice, our focus is on the channel of conspicuous motivation and social influence rather than the direct financial channel. By doing so, we add to existing evidence suggested by Lee and Mori (2015) that higher housing consumption is associated with higher conspicuous demand for non-housing goods.

Finally, findings of this paper are relevant to the recent literature on the role of social networks in understanding household financial decisions. Guiso, Sapienza, and Zingales (2013) provide evidence of social influence on households' decisions to strategically default on their mortgages. Bailey et al. (2016) document the importance of accounting for social networks to understand the home purchase decision. Agarwal, Qian, and Zou (2017) and Di Maggio et al. (2016) find evidence consistent with a "keep-up-with-the-Joneses" effect on household consumption. This paper contributes to the literature by highlighting the role of residential circles in explaining household indebtedness through the mechanism of conspicuous consumption. 


\section{Data and Methods}

\subsection{Data}

We use a unique proprietary dataset that contains consumer financial transactions between April 2010 and March 2012 of approximately 180,000 customers from the leading bank in Singapore. ${ }^{5}$ For individuals in our sample, we have monthly statement information on each of their credit cards and debit cards with the bank, including balance, spending, credit card limit, credit card payment, and debt. Close to $30 \%$ of all personal consumption in the country is done using credit and debit cards. ${ }^{6}$ The dataset, which covers all transactions done with credit cards and debit cards that individuals hold with the bank, contains transaction-level information, including transaction amount, transaction date, merchant name, and merchant category. It is reported that Singapore cardholders own, on average, 3.3 credit cards per individual, ${ }^{7}$ and individuals in our analysis sample each own an average of 2.9 credit cards. Thus, our analyses are based on most - if not all - credit card and debit card transactions being done by each individual in our sample, although it is possible that these individuals still own credit cards with other banks. Their consumption using these credit cards is missing in our dataset. The dataset also contains a rich set of demographic information on each individual, including age, gender, income, type of residence, residential postal code ${ }^{8}$ nationality, ethnicity, and occupation. ${ }^{9}$

\footnotetext{
${ }^{5}$ The bank has more than 4 million customers, or $80 \%$ of the entire population of Singapore. Our sample is a random representative sample of the bank's customers. The same dataset was used in Agarwal and Qian (2014). ${ }^{6} \mathrm{We}$ expect that a much larger proportion of conspicuous consumption, which is the main focus on our study, is done by credit cards.

${ }^{7}$ Singapore top in Asia in credit cards owned per person: survey (April 13, 2012). Retrieved from https://sg.finance.yahoo.com/news/singapore-top-asia-credit-cards-105414790.html.

${ }^{8}$ Unlike in the United States, a postal code in Singapore is assigned to a building representing a single-family house or a building with multiple apartment units so it is a very precise measure of residential location.

${ }^{9}$ Occupation variable is a crude measure showing only whether individuals are "professional" or not.
} 
Following Agarwal and Qian (2014), we first compute credit card spending by adding up the monthly spending for all credit card accounts for each individual. Debit card spending is computed by adding up the monthly spending for all debit card accounts for each individual. All of our consumption measures are based on total credit card and debit card spending. However, we exclude transactions at stores outside of Singapore because they may be affected by other factors such as the opportunity and probability of going abroad as well as potential changes in consumption behavior when traveling abroad. Considering the entry barrier of stores, we also exclude transactions at auction houses for the calculation of card spending. ${ }^{10}$

Our credit card data do not offer the information on the home values of one's residence, which may be associated with individuals' consumption and indebtedness. Therefore, we obtain the universal transaction data of HDBs and condos from the Housing and Development Board and the Real Estate Information System database managed by the Urban Redevelopment Authority, respectively. We calculate the mean price and size of transacted units at each postal code over the credit card sample period of 2010-2012 and match this information with individual observations in the credit card data by using the postal code. Thus, the home values and sizes used for the following analyses are proxied at the level of each building of HDBs or condos instead of each unit. To account for potential differences in housing equity, we also calculate the average annual rate of house price appreciation over the period of 2000-2012 at the two-digit postal sector level separately for HDBs and condos. ${ }^{11}$

\footnotetext{
${ }^{10}$ Therefore, we exclude individuals who made card transactions only at foreign stores or auction houses during the entire study period.

11 The postal sector is represented by the first two digits of the postal code, and Singapore is divided into 82 sectors. The mean of this appreciation rate for condos is quite similar to that for HDBs but the standard deviation is slightly higher for condos.
} 


\subsection{Measures}

For the main measure of conspicuous consumption, we start with all local stores listed in our credit card data in merchant categories that are likely to sell visible conspicuous goods based on Heffetz (2011). ${ }^{12}$ We rank these stores by the average per-transaction amount spent by all consumers in our initial sample and define the top $10 \%$ stores $^{13}$ as conspicuous stores. ${ }^{14}$ By doing so, we identify stores where sample individuals purchase the most expensive conspicuous goods that are visible to others. Because the purpose of conspicuous consumption is to flaunt wealth to others, conspicuous individuals would want to consume more at these stores where others spend a lot. Appendix A-1 and Table A1 provide details of the definition of conspicuous stores, that follows Heffetz (2011). In addition, we use the definition that follows Charles, Hurst, and Roussanov (2009) (hereafter CHR) for the robustness check. The categories defined in CHR (2009) are more limited and the stores in these categories are more likely to sell visible and portable goods.

Next, we calculate conspicuous consumption of individuals as follows:

$$
\text { Conspicuous Consumption }_{i t}=\frac{\frac{C S_{i m 1}}{T S_{i m 1}}+\frac{C S_{i m 2}}{T S_{i m 2}}+\frac{C S_{i m 3}}{T S_{i m 3}}}{3} \text {, }
$$

\footnotetext{
${ }^{12}$ We use the store-based measure for our analysis mainly because our credit card data do not provide separate information on the merchant name. And it is quite challenging to extract the merchant name from each store as it does not appear in the exactly same format (sometimes incomplete) across different stores. We do not believe this would be a very serious issue because any stores with the same luxury brands in Singapore are likely to be ranked high in terms of the average per-transaction amount. It is quite unlikely that a specific store only sells chip stuffs to all credit card holders in the sample.

${ }^{13}$ The top $20 \%$ stores are used for the robustness check.

${ }^{14}$ Appendix A-2 provides summary statistics on transactions made in these conspicuous stores, and Appendices A-3 and A-4 show examples of conspicuous stores. As shown in Appendix A-2, conspicuous stores are stores in which individuals in the initial sample spent an average of \$2,011 in one transaction. Appendix A-3 and A-4 show that these stores include luxury brand stores, such as ROLEX (rank: 1), BVLGARI (rank: 7), PATEK PHILIPPE (rank: 8), IWC (rank: 10), HARRY WINSTON (rank: 18), and BALLY (rank: 4,894). Even at other conspicuous stores with lower ranks (Appendix A-4), sample individuals spent more than $\$ 668$ per transaction.
} 
where $\mathrm{CS}_{i m}$ is the card spending at local conspicuous stores by individual $i$ in month $m$ and $\mathrm{TS}_{i m}$ is the total card spending at any local store by individual $i$ in month $m$. We then average this relative ratio of conspicuous consumption for each quarter $t$. By using the fraction of spending at conspicuous stores out of the total card spending, we attempt to indirectly control for potential differences in real disposal income and general consumption patterns between condo and HDB residents. ${ }^{15}$ We believe that our measure more precisely captures real conspicuous desire reflected in non-housing consumption than measures used in previous research that relied on the Consumer Expenditure Survey or the transaction data from a single retail chain (e.g., Charles, Hurst, and Roussanov, 2009; Vissing-Jorgensen, 2012).

Another important measure of our study is consumer indebtedness. We account for both the credit card debt balance and the credit card debt under delinquency. For the credit card debt, we compute a quarterly mean of the monthly credit card debt balances which are the difference between the current month's credit card payment and the previous month's balance. We generate the measure of credit card delinquency by taking the quarterly mean of the monthly credit card debt balances that are delinquent for 30-210 days (i.e., 30, 60, 90, 150, 180, and 210 days ${ }^{16}$ ).

\subsection{Sample}

As demographic characteristics are likely to play an important role in consumption desire and behavior, we first limit our sample to individuals with the proper information on age, income,

\footnotetext{
${ }^{15}$ Higher real disposable income should influence not only spending at conspicuous stores but also the total card spending.

${ }^{16}$ Our data do not contain information on debt that is delinquent for periods longer than 210 days. By nature, this delinquency measure has many zero values. Therefore, it represents both the likelihood of experiencing delinquency and the amount of delinquent debt.
} 
type of residence, nationality, ethnicity, marital status, and residential postal code. To identify conspicuous consumers using two residential circles in Singapore - public (HDB) or private (condo) - we exclude individuals whose residence type is a foreign address, an office, a post office box, or unknown. After eliminating individuals with missing demographic information and only with invalid transactions as well as those who reside in neither a HDB nor a condo, our sample size is reduced to 122,531 individuals from the initial sample of 187,249 . For the regression analyses, we arrange all variables in the data at the individual-quarter level. Summary statistics based on the sample of 122,531 individuals are reported in Table 1 . Table 1 compares conspicuous consumption behavior, indebtedness, and socioeconomic attributes between condo and HDB residents. Compared with HDB residents, condo residents spent much more at conspicuous stores regardless of the definition of such stores. For example, at the top $10 \%$ conspicuous stores based on the definition of Heffetz (2011), condo residents spent \$156 per month while HDB residents spent $\$ 62$. Condo residents also carry larger credit card debts (\$612) than HDB residents (\$595) and slightly larger credit card debts under delinquency.

[Insert Table 1 about Here]

Although these results may imply a difference in conspicuous consumption and indebtedness between condo and HDB residents, it is clear that condo residents are not directly comparable with HDB residents in several key dimensions. For example, because condo residents have considerably higher monthly incomes $(\$ 9,916)$ than HDB residents $(\$ 4,478)$, condo residents may simply have greater economic capacity to buy more expensive goods than do HDB residents. It is also notable that condo residents live in more expensive and larger homes and are older than HDB residents. Condo residents are more likely to be foreigners, married, and educated with bachelor degree but less likely to be Malay. If individuals' income and 
demographic attributes are associated with their economic capacity for and patterns of consumption, these attributes, instead of conspicuous motivation, may drive more conspicuous consumption and higher indebtedness among condo residents.

\subsection{Identification strategy}

Our goal is to minimize potential confounding issues and provide a causal interpretation of the role of conspicuous consumption to indebtedness. To do so, we identify conspicuous consumers using residential circles and employ the standard logic of a counterfactual causal inference design (e.g., Rosenbaum, 2002; Morgan and Winship, 2007) ${ }^{17}$ Our potential treatment group is comprised of all sample individuals residing in condos, and those who reside in HDBs belong to the potential comparison group. Among the pool of 106,450 HDB residents (Table 1), we select the closest match for each individual residing in condos by using both manual and propensity score matching (PSM) procedures. First, we manually match within the strata by income decile to ensure no difference in income between treatment and comparison groups, because income is directly related to economic capacity for conspicuous consumption.

Next, within each stratum, we match each treatment observation with a comparison observation based on the criteria that are potentially associated with (conspicuous) consumption behavior, including age, gender, and marital status. We also use the price per square meter and size of residence at the six-digit postal code level as matching criteria to control for potential differences

\footnotetext{
17 Two conditions are necessary to obtain "strong ignorability" of any confounding or potential selection bias to treatment (Rosenbaum and Rubin, 1983). First, the treatment and comparison groups must have no significant difference in the means on all variables that could influence the treatment assignment. Second, the treatment and comparison groups must have common support in their distributions.
} 
in housing consumption and potential housing wealth between condo and HDB residents. ${ }^{18,19} \mathrm{We}$ use one-to-one matching with no replacement closest in the propensity score within a 0.003 caliper width to improve covariate balance and reduce bias. During the matching process, we lost some individuals in our treatment groups who were left unmatched because no one in the comparison group was in the same income decile or had a propensity score within a 0.003 caliper width of these individuals' scores. ${ }^{20}$ Our final sample size after matching is 2,629 individuals for the treatment group and 2,629 for the comparison group.

Table 2 summarizes the quality of the matched sample. Our treatment group (condo residents) and comparison group (HDB residents) are highly homogeneous with respect to income, value of residence per square meter, size of residence, age, and marital status. The mean differences of these variables are reduced by more than $85 \%$ as a result of matching. In the matched sample, there are slightly more females in the treatment group than in the comparison group. However,

\footnotetext{
${ }^{18}$ Condos usually provide better amenities than HDBs, such as a swimming pool and gym, and residential choice may be driven by demand for these amenities rather than conspicuous motivation. If this assumption is true, those who sorted into condos simply have higher demand for such amenities than those who chose HDBs and this difference should not affect their non-housing conspicuous consumption. On the other hand, it is less likely but possible that HDB residents have similarly high desire for such amenities but made suboptimal residential choices. As a result, they may end up spending on similar amenities in addition to their housing consumption. We do not think this additional spending on amenities is huge as community centers in most HDB estates offer various exercise options at minimal costs and the average cost of the monthly membership of private fitness centers in Singapore is less than $\$ 100$. To further address this concern, however, we attempt to use the amount of spending at conspicuous stores (instead of its fraction out of the total card spending) which is not related to the non-conspicuous consumption as the measure of conspicuous consumption, and estimation results are robust.

${ }^{19}$ Since the size of condos is generally larger than the size of HDBs before matching, it is possible that condo residents share their rents among more people to reduce housing costs and secure higher disposable income. While our credit card data do not offer the information on housing tenure status, we try three things to rule out this possibility. First, we use the floor area as a matching criterion to make sure that the condo size is not larger that the HDB size. Second, based on the Singapore Census of Population 2010, we find no significant difference in household size other than a higher probability of 1-person households among condo residents. Finally, we redo our analysis with the subsample of only Singaporeans who are most likely to be homeowners (the average homeownership rate for Singaporeans is around 90\%) in the later robustness check.

${ }^{20}$ We lose many observations mainly given our strict matching criteria including exact matching for income deciles and a very small caliper size, which we believe are critical to identify comparable treatment and comparison groups. We conduct a robustness check by removing the caliper restriction and report the result in Appendix C.
} 
this does not undermine the quality of our matched sample because the direction of this difference is not in favor of our hypothesis. ${ }^{21}$ Furthermore, all variables including the proportion of females, satisfy Cochran's rule of thumb. This means that none of these variables differs by more than a quarter of a standard deviation of the respective variable between the treatment and comparison groups, suggesting that our matched sample is well balanced (Cochran, 1968; Ho et al., 2007). ${ }^{22}$ Finally, Figure 1 demonstrates that the distributions of monthly income, value of residence per square meter, size of residence, and age of condo and HDB residents are quite homogeneous after matching. Therefore, we have a panel of reasonably balanced treatment and comparison individuals, which allows us to claim that any observed treatment effect on conspicuous consumption and indebtedness is not biased by differences between treatment and comparison groups in individual socioeconomic characteristics.

\section{[Insert Table 2 about Here]}

\section{[Insert Figure 1 about Here]}

We argue that our identification strategy is convincing in identifying the conspicuous motivation that should drive the direct relationship between conspicuous consumption and household indebtedness. First, unlike gated communities in other countries, the important function of condos in Singapore represents exclusive membership and prestigious lifestyle rather than ensuring security (Pow, 2009). ${ }^{23}$ Next, there is anecdotal evidence on a closer association between one's residential circle and social networks in Singapore. According to the Study of

\footnotetext{
${ }^{21}$ Base on the unmatched sample, Table 1 shows that condo residents who spent more at conspicuous stores and carried more credit card debt were less likely to be female.

${ }^{22} \mathrm{~A} t$-test of the mean difference with respect to each of these variables confirms that the differences are not statistically significant except for the proportion of females. However, we do not report the results of the $t$-tests, because balance is a characteristic of the observed sample and not a hypothetical population. Thus, $t$-statistics below 2 , for example, have no special relevance for assessing balance.

${ }^{23}$ Hence, many Singaporeans set the condo purchase as their status enhancement target and aspire to be identified through such exclusive "landscape of privilege" (Duncan and Duncan, 2003; Pow, 2009).
} 
Social Capital in Singapore done by the NUS Institute of Policy Studies (2017), Singaporeans who reside in private housing have more friends who also reside in private housing while people residing in public housing are more likely to form social ties among themselves. ${ }^{24}$ Hence, comparisons of socioeconomic standing among peers are most likely to happen in residential circles. Finally, the relative income position of condo residents is expected to be lower in their residential circles than their matched counterparts in HDBs, given that the average income level in condos is much higher than in HDBs, as shown in Table $1 .{ }^{25}$ As demonstrated by previous research (Grinblatt, Keloharju, and Ikaheimo, 2008; Charles, Hurst, and Roussanov, 2009; Bricker, Ramcharan, and Krimmel, 2014; Georgarakos, Haliassos, and Pasini, 2014), lower (perceived) own income compared with peers has a significant association with conspicuous consumption and debt.

\section{Results}

\subsection{Residential circles and conspicuous consumption}

First, we attempt to test whether condo residents with higher conspicuous motivation are indeed engaged in more conspicuous consumption than matched HDB residents. Table 3 reports the results of quarterly regressions (Panel-GLM with $\log \operatorname{link}^{26}$ ) that examine the relationship between residential circles (condo vs. HDB) and conspicuous consumption:

\footnotetext{
${ }^{24}$ On average, public housing residents have fewer than one friend residing in private housing while private housing residents have more than three friends residing in private housing in their social network.

${ }^{25}$ To verify this, we compute the income deciles separately for two residential circles (i.e., condo or HDB) within the same postal sector among all individuals in our unmatched sample. We then assign to each individual in the matched sample an income decile, where 1 represents the lowest decile and 10 represents the highest decile. We find that the mean deciles are 4.71 and 7.69 for condo residents and HDB residents in the matched sample, respectively (the difference is statistically significant at the $1 \%$ level).

${ }^{26}$ We use a generalized linear model (GLM) with log link regression using the quasi-maximum likelihood method for all analyses (i.e., Poisson-type regression) because our dependent variables, such as conspicuous consumption and credit card debt, contain many zero values. The ordinary least squares (OLS) tends to underestimate the
} 


$$
\text { Conspicuous Consumption } i t=\alpha+\beta * \text { Condo }_{i}+\gamma * X_{i}+\varepsilon_{i, t} \text {, }
$$

where Conspicuous Consumption ${ }_{i t}$ is the quarterly average of the fraction of monthly card spending made by individual $i$ at conspicuous stores out of the total monthly card spending made by $i$ as shown in Equation (1), Condo is a dummy variable that takes the value of 1 if individual $i$ is a condo resident and 0 if individual $i$ resides in HDB, and $X_{i}$ denotes a vector of socioeconomic control variables. While we include only the condo dummy variable and the constant term in Model 1, we add proxies for wealth and permanent income (price of residence, size of residence, rate of price appreciation of residence, and income) in Model 2 and demographic controls in Model 3. ${ }^{27}$ Regressions are run with the matched sample of 5,258 individuals (2,629 condo residents and 2,629 HDB residents) and at quarterly frequency.

$$
\text { [Insert Table } 3 \text { about Here] }
$$

As shown in Table 3, we find a strongly significant positive effect of residing in condos on conspicuous consumption. Although individuals in the matched sample share similar income, residence, and demographics, the fraction of spending at conspicuous stores out of the total card spending is $25 \%{ }^{28}$ higher among condo residents compared with their HDB counterparts (Model 3). In addition, the point estimate of the condo variable is quite consistent across models, suggesting that unobserved factors associated with expected disposable income or wealth would not contaminate our results significantly.

\footnotetext{
treatment effects in such a situation. The Poisson quasi-maximum-likelihood method has been reported to be more appropriate than log-linearized OLS, even when the dependent variable is a continuous variable (Gourieroux, Montfort, and Trognon, 1984; Silva and Tenreyro, 2006). Therefore, our regressions follow the assumption that $\ln \{\mathrm{E}(\mathrm{y})\}=\mathrm{xB}, \mathrm{y} \sim$ Poisson, where $\mathrm{y}$ is a dependent variable and $\mathrm{x}$ is a vector of covariates. As a robustness check, we run OLS regressions and find that our main analysis results are quite robust except for larger standard errors.

${ }^{27}$ Even after matching, simply comparing the difference in the means of outcomes between the treatment and comparison groups assumes that the treatment variable and covariates are unrelated. When this assumption is false, the results are subject to omitted variable bias.

${ }^{28}$ The percentage change is calculated using $100 \times\left(e^{\beta}-1\right)$.
} 
We further investigate the overall consumption patterns and indebtedness of condo residents compared with their matched counterparts in HDBs, and results are presented in Table 4. As expected, all of the conspicuous consumption measures are significantly higher for condo residents than for HDB residents. Next, we find that condo residents in the matched sample own a larger number of credit cards and that a larger proportion of these residents, relative to HDB residents, own the most prestigious type of credit card (Amex Elite) issued by the bank. This further supports the stronger conspicuous desire of condo residents. Finally, we compare consumption patterns between condo and HDB residents in various categories, including inconspicuous, invisible consumption. As shown in Table 4, condo residents spend on average a slightly larger amount in total (\$768) than HDB residents (\$673). However, this excess spending by condo residents is strongly evident in consumption categories that are visible and conspicuous, such as travel, durable, apparel, transportation, and dining. In contrast, condo residents do not spend significantly more at stores in the categories of service and supermarket, which tend to sell more invisible and/or inconspicuous wellbeing goods. Table 4 also shows that condo residents carry higher credit card debt and delinquent credit card debt without controlling for socioeconomic attributes.

\section{[Insert Table 4 about Here]}

To summarize, the results in Tables 3 and 4 clearly suggest that condo residents with potentially higher conspicuous motivation indeed spend more on conspicuous goods and less on inconspicuous wellbeing goods compared with their matched counterparts in HDBs. This finding is consistent with the theoretical prediction of Eaton and Eswaran (2009). As mentioned in the previous section, residential sorting (i.e., concentration of resident peers with the similar level of conspicuous desire) and relative economic standing have likely motivated conspicuous 
consumption among condo residents. These results support our identification strategy that uses quasi-experiment matching based on their residential circles to define the level of conspicuous motivation. They also confirm that our conspicuous consumption measure reflects conspicuous motivation and not just expenditures on higher-priced goods.

\subsection{Conspicuous consumption and indebtedness}

Having established that individuals with higher conspicuous motivation are engaged in more conspicuous consumption, we move to examine the role of conspicuous consumption in indebtedness. Table 5 shows the results of quarterly regressions (Panel-GLM with log link) that examine the relationship between residential circles (condo vs. HDB) and household indebtedness using the same matched sample as follows:

$$
\text { Indebtedness }_{i t}=\alpha+\beta * \text { Condo }_{i}+\gamma * X_{i}+\varepsilon_{i, t},
$$

where Indebtedness $s_{i t}$ is the quarterly average of monthly credit card debt balance carried by individual $i$ for Panel A and the credit card debt that is delinquent for more than 30 days for Panel B, Condo $i$ is a dummy variable that takes the value of 1 if individual $i$ is a condo resident and 0 if individual $i$ resides in HDB, and $X_{i}$ denotes a vector of socioeconomic control variables.

We find that condo residents carry more credit card debt and more delinquent debt than matched HDB residents by $7 \%$ and $108 \%$, respectively, controlling for individual socioeconomic and residential characteristics (Model 3). ${ }^{29} \mathrm{We}$ argue that this increase is significant. Considering the average monthly credit card debt (\$669) and the debt under delinquency (\$18) for all individuals in the matched sample, $7 \%$ and $108 \%$ increases translate into $\$ 47$ and $\$ 19$, respectively, keeping

\footnotetext{
${ }^{29}$ Similar to results shown in Table 3, the point estimate of the condo variable is quite consistent across our models.
} 
other variables constant. Together with the previous finding, this suggests that people with higher conspicuous motivation tend to consume significantly more on expensive, visible goods and this consumption may sometimes go beyond their financial capacity and result in debt and delinquencies. $^{30}$

\section{[Insert Table 5 about Here]}

Next, to examine the direct relationship between conspicuous consumption and indebtedness, we add the conspicuous consumption measure and the interaction term between this and the condo dummy variable to the quarterly regression shown in Equation (3) as follows:

$$
\begin{aligned}
& \text { Indebtedness }_{i t}=\alpha+\delta * \text { Conspicuous Consumption }_{i t-1}+\beta * \text { Condo }_{i}+\theta * \\
& \left(\text { Condo }_{i} \times \text { Conspicuous Consumption }_{i t-1}\right)+\gamma * X_{i}+\varepsilon_{i, t},
\end{aligned}
$$

where Indebtedness $i t$ is the quarterly average of monthly credit card debt balance carried by individual $i$ for Panel A and the credit card debt that is delinquent for more than 30 days for Panel B, Conspicuous Consumption ${ }_{i t-1}$ is the lagged quarterly average of the fraction of monthly card spending at conspicuous stores out of the total monthly card spending $i$, Condo $_{i}$ is a dummy variable that takes the value of 1 if individual $i$ is a condo resident and 0 if individual $i$ resides in HDB, and $X_{i}$ denotes a vector of socioeconomic control variables. Our main focus is on the interaction term, Condo $\mathrm{x}$ Conspicuous Consumption Ct- 1.

Table 6 summarizes the results. First, consistent with the results in Table 5, condo residents carry significantly higher credit card debt (9\% more as shown in Panel A) and higher delinquent credit card debt (134\% more as shown in Panel B) than HDB residents. More importantly, the results of

\footnotetext{
${ }^{30}$ To test the effect on the extensive margin of delinquency, we also run the regression where the dependent variable is a dummy variable that takes the value of 1 if individuals have any delinquent debt and 0 otherwise. The coefficient for the Condo variable is positive but statistically insignificant. This means that conspicuous motivation itself does not have statistical power to explain the external margin of delinquency, but the direction is consistent.
} 
the interaction term between condo and conspicuous consumption suggest that condo residents who spend more at conspicuous stores carry significantly higher credit card debt and delinquent credit card debt compared with other condo residents. In contrast, the relationship between conspicuous consumption and credit card debt is negative among HDB residents, as is evident from the coefficients of conspicuous consumption $(B=-0.095 ; z=-37.69$ in Panel $A$ and $B=-$ 2.641; $z=-48.61$ in Panel B). Thus, HDB residents who spend more at conspicuous stores carry less credit card debt and delinquent credit card debt, potentially because their consumption is less driven by conspicuous motivation. ${ }^{31}$

\section{[Insert Table 6 about Here]}

The results in Tables 5 and 6 together suggest that consumption of visible luxury goods leads to higher indebtedness only when consumers have strong conspicuous motivation. In other words, it is conspicuous consumption not consumption of expensive goods that has negative financial consequences. These results reinforce the importance of identifying consumers with conspicuous motivation to precisely investigate the role of conspicuous consumption in indebtedness. For example, because Vissing-Jorgensen (2012) does not identify consumers with different levels of conspicuous motivation, the positive relationship between luxury consumption and credit default shown in her study may be underestimated.

\subsection{Heterogeneity among conspicuous consumers}

Not all condo residents with potentially stronger conspicuous motivation would spend more at conspicuous stores, thus leading to higher indebtedness. We examine the potential heterogeneity

\footnotetext{
31 They may also be better than condo residents at substituting conspicuous desires between housing and nonhousing goods. A significant price difference exists between condos and HDBs (see Table 1). In a rational framework, individuals that chose condos should have responded to higher housing costs by consuming less in other categories.
} 
of conspicuous consumption and indebtedness among condo residents in terms of age, gender, marital status, and education level. Table 7 summarizes the results of the quarterly regressions (Panel-GLM with log link) using the same matched sample. ${ }^{32}$

\section{[Insert Table 7 about Here]}

The results of conspicuous consumption models show that, among condo residents that are potentially conspicuous, male individuals actually spent more at conspicuous stores relative to their total card spending (Panel B) while other demographic factors do not have a significant impact on actual conscious consumption patterns. On the other hand, the results of credit card debt models show that the debt behavior significantly differs by demographic factors: among condo residents, younger (Panel A), male (Panel B), single (Panel C), and lower educated (Panel D) individuals carried higher credit card debt balance. These results imply that that age, marital status, and education level that could be proxies for income and wealth tend to play an important role in household indebtedness, regardless of their excess conspicuous consumption.

We also find that more conscious consumption leads to higher debt only among individuals with higher conspicuous motivation. As mentioned above, among condo residents, male individuals spent more at conspicuous stores, and in turn, carried higher credit card debt balance. On the other hand, this link does not hold for HDB residents. For example, Table 7 shows that, among HDB residents, while younger individuals spent more at conspicuous stores, their carried debt amount was no higher than that of others. These results reiterate our previous finding that

\footnotetext{
${ }^{32}$ Conspicuous consumption models follow Equation (2) and Credit Card Debt models follow Equation (3). To these equations, we add the interaction terms between a condo dummy variable and demographic variable which is the main variable of interest for the heterogeneity analyses. For credit card debt models, we focus on the credit card debt balance because the number of delinquent cases is very small for the matched sample and the maximum likelihood method did not converge for specifications with an additional interaction term.
} 
conspicuous motivation is critical in explaining the relationship between conspicuous

consumption and indebtedness, possibly because those with stronger conspicuous motivation have lower capacity to substitute conspicuous desires across different items (e.g., housing vs. non-housing goods) and engage in better financial management.

\subsection{Robustness checks}

First, we test whether our estimation results are robust to different definitions of conspicuous stores. In addition to the measure we use for the main analyses, the top $10 \%$ conspicuous stores based on Heffetz (2011), we re-define conspicuous stores following CHR (2009). As mentioned earlier, the categories defined in CHR (2009) are more limited and the stores in the categories are more likely to sell visible and portable goods. Therefore, purchases at these stores may have a more significant association with conspicuous motivation. We also examine the list of both top $10 \%$ and top $20 \%$ stores based on the rank by average per-transaction amount spent. The results in Appendix B confirm that condo residents in the matched sample are clearly more conspicuous than their HDB counterparts, regardless of the definition of conspicuous stores.

Next, we re-run our analyses using the matched sample that meets more rigorous matching criteria. ${ }^{33}$ Although we use a number of important socioeconomic variables as matching criteria for our main analyses, we now attempt to further address the potential concern that other variables may systematically differ between treatment and comparison groups and are associated

\footnotetext{
${ }^{33}$ For all of these robustness checks, value of residence $(\log )$, size of residence $(\log )$, the rate of price appreciation of residence, income (log), age, female, and married variables are included as control variables. For all matchings, we use the same logit model to estimate the propensity score, for which the dependent variable is the condo dummy and the base independent variables are value of residence per square meter, size of residence, income decile, age, gender, and marital status. One-to-one matching is done with no replacement, where each matched pair is forced to be drawn from the same income decile. We add different criteria for different robustness checks.
} 
with dependent variables. For example, because non-Singaporeans are concentrated in condos, our results may be subject to selection bias if they have systematically different conspicuous motivation from that of Singaporean citizens. It is also possible that neighborhoods in which condos and HDBs are located differ and the neighborhood environment beyond residential circles affects individual consumption behavior. Next, arguably, people with higher levels of education may have higher expectations about their future income, and condo residents tend to have higher education, as shown in Table 1. Therefore, expected future income and not conspicuous motivation leads condo residents to spend more on luxury goods and carry higher debt. To address these concerns, we create a series of new matched samples only among Singaporeans (Panel A), those who reside in the same postal sector (Panel B), individuals whose highest degree is a Bachelor's (Panel C). The results shown in Appendix C (Panel A, B, C) using these samples show that the treatment effects of residing in condos on conspicuous consumption and credit card debt are consistent with our main results.

The opposite potential concern is that our matching process may result in large sample reduction which may affect the external validity of our results. We therefore create the matched sample without using any caliper (vs. 0.003 for the main analyses) based on the same matching criteria used for the main matched sample. Panel D of Appendix C confirms that the results are robust even without caliper restriction. Panel E further shows the results of the regressions that use the unmatched sample of 122,231 without any matching algorithm, and confirms that they are consistent with our main results. 
Lastly, we test whether our analysis results using home values at the six-digit postal code level to control for housing costs are robust to housing tenure status, for which our data do not provide information. While most HDB residents are likely to be homeowners, there would be more renters among condo residents in our sample. ${ }^{34}$ If housing costs significantly differ between owners and renters, therefore, this difference may affect their disposable income, and in turn, non-housing conspicuous consumption and indebtedness. ${ }^{35}$ To address this issue, we estimate monthly housing costs for owners of HDBs, owners of condominiums, and renters of condominiums. For owners, we use the median values of HDBs and condos $(\$ 647,406$ and $\$ 644,500$, respectively) from our matched sample and assume that owners take out an $80 \%$ loan with a 25-year maturity and a $2 \%$ interest rate. Monthly mortgage payments of HDB and condo owners are estimated at $\$ 2,195$ and $\$ 2,185$, respectively. To measure the monthly rent for a condominium with a value of $\$ 644,500$, we identify several condominiums of similar values and collect rental data ${ }^{36}$ for units sized 120 square meters - about the mean size of condominium and HDB units in the matched sample. We find that the monthly rent of the typical condominium in the matched sample should be approximately $\$ 2,800$, which verifies that condo renters' housing costs must be higher than HDB owners' housing costs. ${ }^{37}$ Thus, it is very unlikely that higher conspicuous consumption and higher debt among condo residents (both owners and renters) relative to among HDB owners is attributable to lower housing costs.

\footnotetext{
${ }^{34}$ Among Singaporean citizens and permanent residents, the homeownership rates for HDBs and condos are $92 \%$ and $84 \%$, respectively, as of 2015 . The homeownership rate for foreigners should be lower.

${ }^{35}$ Another possibility is that the household size is larger for condo renters and they share rents to secure higher disposable income. We have tried to rule this out in the prior section.

${ }^{36}$ Rental data are from the Urban Redevelopment Authority in Singapore as of the end of 2012.

${ }^{37}$ While the size of condos is generally larger than the size of HDBs before matching and one may be concerned that condo residents share their rent among several people to reduce housing costs, we use the size of residence as a matching criterion as well as a control variable.
} 


\section{Concluding Remarks}

We identify the different level of conspicuous motivation in the Singapore context on the basis of residential circles, private condominiums, and HDBs, and analyze conspicuous consumption and indebtedness. A series of analyses using the matched sample of individuals that reside in condos and HDBs first confirms that condo residents that are hypothesized to have higher conspicuous motivation were indeed engaged in more conspicuous consumption than HBD residents. They spent more on conspicuous goods but not necessarily on other wellbeing goods, and were more likely to own prestigious credit cards compared with their matched counterparts in HDBs. Our main finding is that condo residents who have greater conspicuous motivation had more credit card debt and credit card debt under delinquency than their matched counterparts in HDBs. Moreover, conspicuous consumption led to higher credit card debt only among condo residents. Finally, among these condo residents, male individuals particularly spent more at conspicuous stores and, in turn, carried higher credit card debt balance.

Our findings provide an important insight into the discussion on recent increases in household indebtedness. Consumption of visible, luxury goods, especially driven by higher conspicuous motivation, makes a significant contribution to indebtedness. Hence, conspicuous motivation provides one possible explanation for why some people consume more than their available economic resources and carry debt. Furthermore, conspicuous consumers seem to have lower capacity to substitute conspicuous desires between different items. As shown in our results, individuals who already made a conspicuous residential choice further increase non-housing conspicuous consumption. In contrast, in a rational framework, they should respond to higher housing costs by consuming less in other categories. Among conspicuous consumers, particular 
concern needs to be given to the group of people who are more vulnerable to higher indebtedness. Our results suggest that male individuals belong to this group.

In terms of conspicuous motivation, our results suggest the importance of individual residential choices. Even in non-Singapore contexts, it is highly plausible that persons with stronger conspicuous desire sort into single family housing units on prestigious streets or multifamily housing complexes with brand names. If they are surrounded by and interact with neighbors who are similarly conspicuous and/or have higher incomes, they are likely to perceive their economic standing as relatively low, motivating them to engage in more conspicuous consumption. In contrast, certain areas may have significant variations in community and locational amenities, such as a swimming pool in a gated community and higher educational quality across different residential circles. Individuals who choose conspicuous residential circles for these amenities and not because of their own conspicuous desire may be exposed to peer effects from conspicuous neighbors. As our results suggest, choosing a conspicuous residential circle on the basis of either their own conspicuous motivation or other reasons could trigger a higher level of non-housing conspicuous consumption that eventually leads to higher debt and delinquency. 


\section{References}

Agarwal, S., Qian, W., 2014. Consumption and debt response to unanticipated income shocks: Evidence from a natural experiment in Singapore. American Economic Review 104(12), 42054230 .

Agarwal, S., Qian, W., Zou, X., 2017. Thy neighbor's misfortune: Peer effect on consumption. Working paper. National University of Singapore.

Bailey, M., Ruiqing C., Kuchler, T., Stroebel, J., 2016. Social networks and housing markets. Working paper. NYU Stern.

Bricker, J., Ramcharan, R., Krimmel, J., 2014. Signaling status: The impact of relative income on household consumption and financial decisions. FEDS working paper. Federal Reserve Board.

Carr, M. D., Jayadev, A., 2015. Relative income and indebtedness: Evidence from panel data. Review of Income and Wealth 61(4), 759-772.

Charles, K. K., Hurst, E., Roussanov, N., 2009. Conspicuous consumption and race. Quarterly Journal of Economics 124(2), 425-467.

Chen, J., Hardin III, W., \& Hu, M., 2018. Housing, wealth, income and consumption: China and homeownership heterogeneity. Real Estate Economics, forthcoming.

Cochran, W. G., 1968. The effectiveness of adjustment by subclassification in removing bias in observational studies. Biometrics 24(2), 295-313.

De Giorgi, G., Frederiksen, A., Pistaferri, L., 2016. Consumption network effects. Working paper. National Bureau of Economic Research.

Di Maggio, M., Kermani, A., Keys, B., Piskorski, T., Ramcharan, R., Seru, A., Yao, V., 2016. Monetary policy pass-through: Household consumption and voluntary deleveraging. American Economic Review, forthcoming.

Drechsel-Grau, M., Schmid, K. D., 2013. Habits and envy: What drives the consumption behavior of U.S. households? Evidence from the PSID, 1999-2009. IMK working paper. Hans Böckler Foundation.

Duncan, J. and N. Duncan., 2003. Landscapes of privilege: The politics of the aesthetic in an American Suburb. London: Routledge.

Eaton, B. C., Eswaran, M., 2009. Well-being and affluence in the presence of a Veblen good. Economic Journal 119(539), 1088-1104. 
Fan, Y., \& Yavas, A., 2018. How does mortgage debt affect household consumption? Micro Evidence from China. Real Estate Economics, forthcoming.

Federal Reserve System. "Consumer credit" Federal Reserve Statistical Release G19. Washington, D.C.: Board of Governors of the Federal Reserve System.

Georgarakos, D., Haliassos, M., Pasini, G., 2014. Household debt and social interactions. Review of Financial Studies 27(5), 1404-1433.

Gourieroux, C., Monfort, A., Trognon, A., 1984. Pseudo maximum likelihood methods: Applications to Poisson models. Econometrica 52(3), 701-720.

Grinblatt, M., Keloharju, M., Ikaheimo, S., 2008. Social influence and consumption: Evidence from the automobile purchases of neighbors. Review of Economics and Statistics 90(4), 735753.

Guiso, L., Sapienza, P., Zingales, L., 2013. The determinants of strategic default on mortgages. Journal of Finance 68(4), 1473-1515.

Güneş, A., \& Tunç, C., 2018. Saving impact of mortgage payments: A microlevel study for the US households. Real Estate Economics, forthcoming.

Heffetz, O., 2011. A test of conspicuous consumption: Visibility and income elasticities. Review of Economics and Statistics 93(4), 1101-1117.

Ho, D. E., Imai, K., King, G., Stuart, E. A., 2007. Matching as nonparametric preprocessing for reducing model dependence in parametric causal inference. Political Analysis 15(3), 199-236.

Hopkins, E., Kornienko, T., 2004. Running to keep in the same place: Consumer choice as a game of status. American Economic Review 94(4), 1085-1107.

Lee, K. O., \& Mori, M., 2016. Do conspicuous consumers pay higher housing premiums? Spatial and temporal variation in the United States. Real Estate Economics, 44(3), 726-763.

Morgan, S., Winship, C., 2007. Counterfactuals and causal inference: Methods and principles for social research, 1st ed. New York: Cambridge University Press.

Pow, C. P. , 2009. Public intervention, private aspiration: Gated communities and the condominisation of housing landscapes in Singapore. Asia Pacific Viewpoint 50(2), 215-227.

Rosenbaum, P., 2002. Observational studies, 2nd ed. Dordrecht: Springer.

Rosenbaum, P., Rubin, D., 1983. The central role of the propensity score in observational studies for causal effects. Biometrika 701, 41-55. doi:10.1093/biomet/70.1.41. 
Silva, J. M. C. S., Tenreyro, S., 2006. The log of gravity. Review of Economics and Statistics 88(4), 641-658.

Sin, C.H., 2002. The quest for a balanced ethnic mix: Singapore's ethnic quota policy examined, Urban Studies 39(8): 1347-1374.

The NUS Institute of Policy Studies, 2017. A Study on Social Capital. https://lkyspp.nus.edu.sg/docs/default-source/ips/study-of-social-capital-in-singapore.pdf.

The NUS Institute of Policy Studies, 2018. National Values Assessment Survey. https://lkyspp.nus.edu.sg/ips/events/details/ips-aadvantage-roundtable-on-the-national-valuesassessment-2018.

Veblen, T., 1899. The theory of the leisure class. New York and London: The Macmillan Company.

Tunc, C., \& Yavas, A., 2016. Not all credit is created equal: Mortgage vs non-mortgage debt and private saving rate in Turkey. Central Bank Review, 16(1), 25-32.

Tunc, C., \& Yavas, A., 2017. Collateral damage: The impact of mortgage debt on US savings. Housing Policy Debate, 27(5), 712-733.

Vinson, P., 2018. House prices and consumption in the United States. Real Estate Economics, forthcoming.

Vissing-Jorgensen, A., 2012. Consumer credit: Learning your customer's default risk from what she buys. Working paper. Northwestern University. 


\section{Table 1 Summary statistics}

Condo residents vs. HDB residents (before matching)

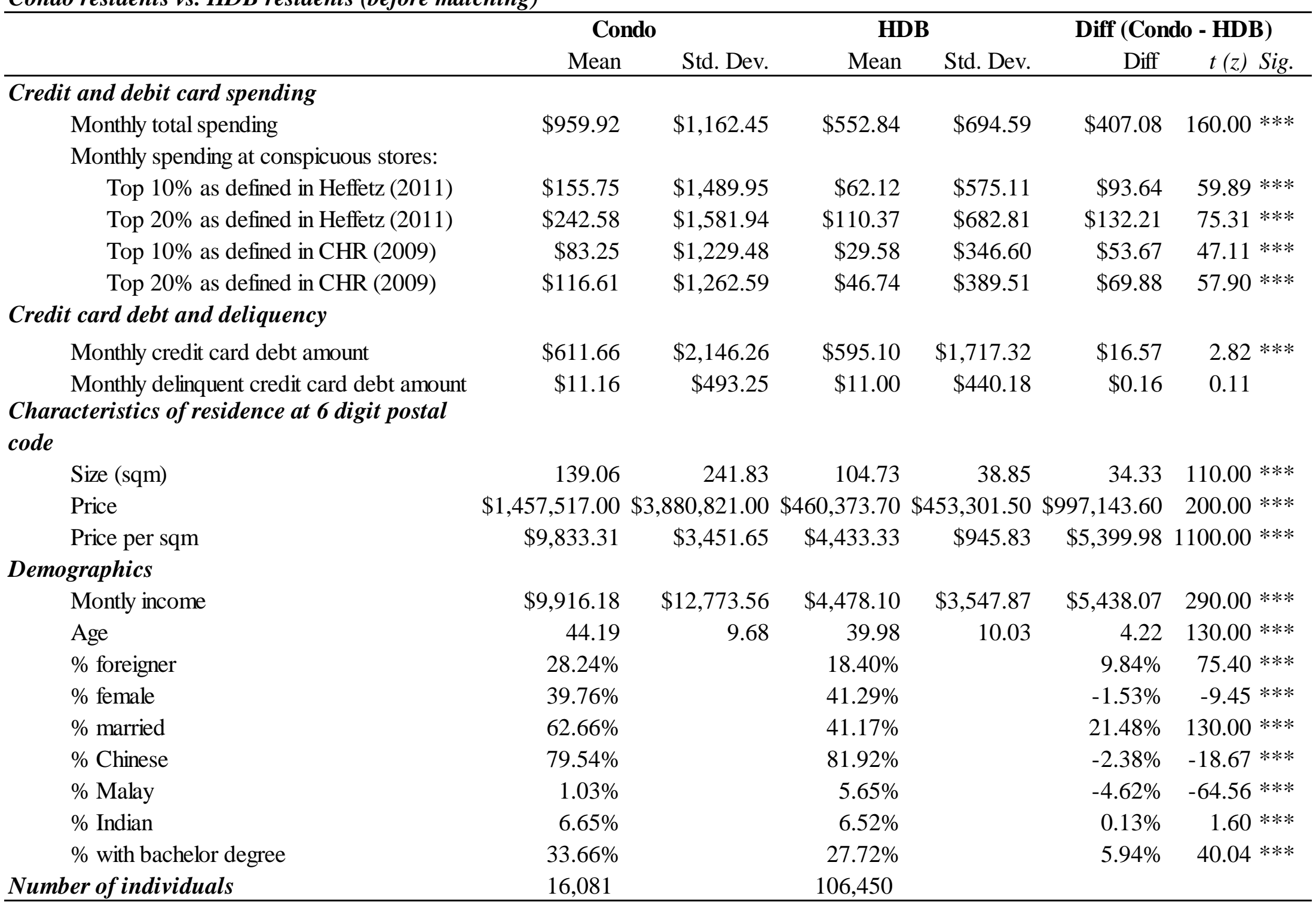


Notes: Table 1 reports summary statistics of the unmatched sample of 122,531 individuals after deleting those with incomplete demographic information. Credit card and debit card spending is computed by adding monthly spending over all card accounts for each individual. Conspicuous stores are defined by ranking all local stores in our dataset that correspond to the categories defined in Heffetz (2011) or CHR (2009) by per-transaction amount. Statistics based on both top 20\% and top $10 \%$ conspicuous stores are summarized. Appendix A-1 provides the details of the definition of conspicuous stores. Credit card debt is computed as the difference between the current month's credit card payment and the previous month's credit card balance. Characteristics of residence are based on information at the postal code level, which refers to each building. All dollar amounts are in local currency (SG\$), and SG $\$ 1=$ US\$0.78 as of February 2011. Variables are winsorized at the $1 \%$ and $99 \%$ levels. $* * *$ indicates significance at the $1 \%$ level, $* *$ indicates significance at the $5 \%$ level, and $*$ indicates significance at the $10 \%$ level. 
Table 2 Quality of propensity score matching (PSM) sample

\begin{tabular}{|c|c|c|c|c|c|c|c|}
\hline & & $\begin{array}{r}\text { Treatment: } \\
\text { Condo }\end{array}$ & $\begin{array}{r}\text { Comparison: } \\
H D B \\
\end{array}$ & Difference & $\%$ reduction & $\begin{array}{r}\text { Difference in } \\
\text { means as } \\
\text { proportion of } \\
\text { standard } \\
\text { deviation } \\
\end{array}$ & $\begin{array}{r}\text { Cochran's } \\
\text { rule of } \\
\text { thumb } \\
\end{array}$ \\
\hline \multirow[t]{2}{*}{ Montly income } & Unmatched & $\$ 9,739.90$ & $\$ 4,309.40$ & $\$ 5,430.50$ & & & \\
\hline & Matched & $\$ 6,508.30$ & $\$ 6,434.30$ & $\$ 74.00$ & 98.60 & 0.013 & $\mathrm{y}$ \\
\hline \multirow{2}{*}{$\begin{array}{l}\text { Price per sqm of residence } \\
\text { ( } 6 \text { digit postal code) }\end{array}$} & Unmatched & $\$ 9,830.80$ & $\$ 4,421.00$ & $\$ 5,409.80$ & & & \\
\hline & Matched & $\$ 6,050.20$ & $\$ 6,388.50$ & $-\$ 338.30$ & 93.70 & 0.141 & $\mathrm{y}$ \\
\hline \multirow{2}{*}{$\begin{array}{l}\text { Size of residence (sqm) } \\
\text { (6 digit postal code) }\end{array}$} & Unmatched & 138.9 & 104.2 & 34.73 & & & \\
\hline & Matched & 112.7 & 117.8 & -5.19 & 85.10 & 0.039 & $\mathrm{y}$ \\
\hline \multirow[t]{2}{*}{ Age } & Unmatched & 43.7 & 39.3 & 4.37 & & & \\
\hline & Matched & 40.7 & 40.7 & 0.03 & 99.20 & 0.003 & $\mathrm{y}$ \\
\hline \multirow[t]{2}{*}{$\%$ female } & Unmatched & $40.2 \%$ & $41.2 \%$ & -0.01 & & & \\
\hline & Matched & $43.7 \%$ & $39.1 \%$ & 0.05 & -329.30 & 0.093 & $\mathrm{y}$ \\
\hline \multirow[t]{2}{*}{$\%$ married } & Unmatched & $61.2 \%$ & $39.4 \%$ & 0.22 & & & \\
\hline & Matched & $48.9 \%$ & $49.5 \%$ & -0.01 & 97.20 & 0.012 & $\mathrm{y}$ \\
\hline
\end{tabular}

Notes: Table 2 compares the statistics of the unmatched sample of 122,531 individuals and the matched sample of 5,258 individuals (2,629 condo residents and 2,629 HDB residents). To estimate the propensity score, we use the logit model, in which the dependent variable is the condo dummy ( 1 for condo residents and 0 for HDB residents) and the independent variables are value of residence per square meter, size of residence in square meter, income decile, age, gender, and marital status. One-to-one matching is done with no replacement, for which each matched pair is forced to be drawn from the same income decile. The column "\% reduction" shows the percentage reduction in the mean difference between condo and HDB residents. "Cochran's rule of thumb" reports whether the mean difference of a variable with the matched sample is less than a quarter of a standard deviation of the respective variable ("y" indicates that the mean difference is smaller than this threshold, suggesting that good balance is achieved after matching). 
Table 3 Residential circles and conspicuous consumption

\begin{tabular}{|c|c|c|c|c|c|c|c|c|c|}
\hline \multirow{3}{*}{ Denendent variabl } & \multicolumn{3}{|c|}{ Model 1} & \multicolumn{3}{|c|}{ Model 2} & \multicolumn{3}{|c|}{ Model 3} \\
\hline & Conspicuou & consur & aption & Conspicuous & consur & mptiol & nspicuous & consur & mption \\
\hline & $B$ & $z$ & & $B$ & $z$ & & $B$ & $z$ & \\
\hline Condo & 0.215 & 3.98 & $* * *$ & 0.217 & 4.02 & $* * *$ & 0.225 & 4.15 & $* * *$ \\
\hline $\begin{array}{r}\text { Price of residence } \\
\text { (log, } 6 \text { digit postal code) }\end{array}$ & & & & -0.033 & -0.43 & & -0.003 & -0.05 & \\
\hline $\begin{array}{r}\text { Size of residence } \\
\text { (log, } 6 \text { digit postal code) }\end{array}$ & & & & -0.088 & -0.62 & & -0.062 & -0.44 & \\
\hline $\begin{array}{r}\text { Rate of price appreciation } \\
\text { of residence }\end{array}$ & & & & & & & & & \\
\hline (2 digit postal sector) & & & & -0.503 & -0.34 & & -0.607 & -0.41 & \\
\hline Income (log) & & & & 0.070 & 2.34 & $* *$ & 0.081 & 2.67 & $* * *$ \\
\hline Age & & & & & & & -0.014 & -4.47 & $* * *$ \\
\hline Female & & & & & & & -0.194 & -3.45 & $* * *$ \\
\hline Married & & & & & & & 0.092 & 1.63 & $*$ \\
\hline Constant & -3.317 & -82.48 & $* * *$ & -3.031 & -3.45 & $* * *$ & -3.036 & -3.47 & $* * *$ \\
\hline Number of observations & 34,117 & & & 34,117 & & & 34,117 & & \\
\hline Number of individuals & 5,258 & & & 5,258 & & & 5,258 & & \\
\hline
\end{tabular}

Notes: Table 3 summarizes the results of quarterly regressions (Panel-GLM with log link) that examine the relationship between residential circles (condo vs. HDB) and conspicuous consumption using the matched sample. The dependent variable of "conspicuous consumption" is the quarterly average of the fraction of monthly card spending at the top $10 \%$ conspicuous stores based on Heffetz (2011) out of the total monthly card spending. The main independent variable is the condo dummy variable that takes the value of 1 if individuals are condo residents and 0 if they are HDB residents. Model 1 includes only the condo dummy and the constant term. Model 2 adds proxies for wealth and permanent income. Model 3 also adds the demographic controls. *** indicates significance at the $1 \%$ level, $* *$ indicates significance at the $5 \%$ level, and $*$ indicates significance at the $10 \%$ level. 
Table 4 Consumption and indebtedness patterns of individuals in the matched sample

\begin{tabular}{|c|c|c|c|c|}
\hline & $\begin{array}{r}\text { Treatment: } \\
\text { Condo }\end{array}$ & $\begin{array}{r}\text { Comparison: } \\
H D B\end{array}$ & $\begin{array}{r}\text { Diff: } \\
\text { Condo-HDB } \\
\end{array}$ & \\
\hline \multicolumn{5}{|l|}{ Conspicuous consumption } \\
\hline \multicolumn{5}{|l|}{ Monthly spending at conspicuous stores: } \\
\hline Top $10 \%$ as defined in Heffetz (2011) & $\$ 118.75$ & $\$ 83.13$ & $\$ 35.62$ & $* * *$ \\
\hline Top $20 \%$ as defined in Heffetz (2011) & $\$ 190.88$ & $\$ 140.22$ & $\$ 50.66$ & $* * *$ \\
\hline Top $10 \%$ as defined in CHR (2009) & $\$ 56.54$ & $\$ 36.83$ & $\$ 19.71$ & $* * *$ \\
\hline Top $20 \%$ as defined in CHR (2009) & $\$ 80.20$ & $\$ 56.88$ & $\$ 23.32$ & $* * *$ \\
\hline \multicolumn{5}{|l|}{ Credit card accounts } \\
\hline Number of credit cards held & 3.14 & 2.97 & 0.17 & $* * *$ \\
\hline$\%$ with Amex Elite & $1.71 \%$ & $1.02 \%$ & $0.69 \%$ & $* * *$ \\
\hline \multicolumn{5}{|l|}{ Monthly spending } \\
\hline Total & $\$ 768.28$ & $\$ 672.82$ & $\$ 95.46$ & $* * *$ \\
\hline Travel & $\$ 148.02$ & $\$ 131.83$ & $\$ 16.19$ & $* * *$ \\
\hline Durable & $\$ 113.34$ & $\$ 87.35$ & $\$ 25.99$ & $* * *$ \\
\hline Apparel & $\$ 105.20$ & $\$ 81.61$ & $\$ 23.59$ & $* * *$ \\
\hline Transportation & $\$ 80.33$ & $\$ 65.27$ & $\$ 15.06$ & $* * *$ \\
\hline Dining & $\$ 93.15$ & $\$ 80.51$ & $\$ 12.63$ & $* * *$ \\
\hline Service & $\$ 223.42$ & $\$ 220.27$ & $\$ 3.15$ & \\
\hline Online & $\$ 25.90$ & $\$ 22.67$ & $\$ 3.23$ & $* * *$ \\
\hline Supermarket & $\$ 34.77$ & $\$ 37.40$ & $-\$ 2.63$ & $* * *$ \\
\hline Entertainment & $\$ 31.37$ & $\$ 30.02$ & $\$ 1.35$ & $*$ \\
\hline \multicolumn{5}{|l|}{ Indebtedness } \\
\hline Monthly credit card debt amount & $\$ 686.86$ & $\$ 651.95$ & $\$ 34.91$ & $* *$ \\
\hline Monthly delinquent credit card debt amount & $\$ 23.81$ & $\$ 11.97$ & $\$ 11.84$ & $* *$ \\
\hline Number of individuals & 2,629 & 2,629 & & \\
\hline
\end{tabular}

Notes: Table 4 summarizes overall consumption patterns and indebtedness of our matched sample of condo and HDB residents. To enhance the convenience for readers, conspicuous consumption measures are shown as the dollar amount of consumption at conspicuous stores instead of its fraction out of the total card spending. "Amex Elite" is the most prestigious type of credit card issued by the bank. All dollar amounts are in the local currency (SG\$), and SG\$1 = US\$0.78 as of February 2011. Variables are winsorized at the $1 \%$ and $99 \%$ levels. *** indicates significance at the $1 \%$ level, $* *$ indicates significance at the $5 \%$ level, and $*$ indicates significance at the $10 \%$ level. 
Table 5 Residential circles and credit card indebtedness

Panel A: Total credit card debt

\begin{tabular}{|c|c|c|c|c|c|c|c|c|c|}
\hline \multirow[t]{2}{*}{ Dependent variable: } & \multicolumn{3}{|c|}{$\begin{array}{c}\text { Model } 1 \\
\text { Credit card debt }\end{array}$} & \multicolumn{3}{|c|}{$\begin{array}{c}\text { Model } 2 \\
\text { Credit card debt }\end{array}$} & \multicolumn{3}{|c|}{$\begin{array}{c}\text { Model } 3 \\
\text { Credit card debt }\end{array}$} \\
\hline & $B$ & $z$ & & $B$ & $z$ & & B & $z$ & \\
\hline Condo & 0.052 & 124.59 & $* * *$ & 0.055 & 132.13 & $* * *$ & 0.072 & 171.47 & $* * *$ \\
\hline $\begin{array}{r}\text { Price of residence } \\
(\log , 6 \text { digit postal code })\end{array}$ & & & & 0.000 & -0.54 & & -0.014 & -24.38 & $* * *$ \\
\hline $\begin{array}{r}\text { Size of residence } \\
(\log , 6 \text { digit postal code })\end{array}$ & & & & 0.106 & 100.36 & $* * *$ & 0.072 & 66.46 & $* * *$ \\
\hline $\begin{array}{l}\text { Rate of price appreciation } \\
\text { of residence }\end{array}$ & & & & 5348 & 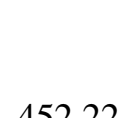 & $* * * *$ & 4023 & 41687 & $* * *$ \\
\hline Income (log) & & & & 0.084 & 355.56 & $* * *$ & 0.050 & 221.71 & $* * *$ \\
\hline Age & & & & & & & 0.013 & 573.34 & $* * *$ \\
\hline Female & & & & & & & -0.367 & -806.13 & $* * *$ \\
\hline Married & & & & & & & -0.088 & -202.38 & $* * *$ \\
\hline Constant & 6.480 & 22000.00 & **** & 5.586 & 853.23 & $* * *$ & 5.835 & 889.96 & $* * *$ \\
\hline Number of observations & 34,117 & & & 34,117 & & & 34,117 & & \\
\hline Number of individuals & 5,258 & & & 5,258 & & & 5,258 & & \\
\hline
\end{tabular}

Panel B: Delinquent credit card debt

\section{Model $1 \quad$ Model $2 \quad$ Model 3}

Dependent variable: Delinquent credit card debt Delinquent credit card debt Delinquent credit card debt

\begin{tabular}{|c|c|c|c|c|c|c|c|c|c|}
\hline & $B$ & $z$ & & $B$ & $z$ & & $B$ & $z$ & \\
\hline Condo & 0.686 & 171.88 & $* * *$ & 0.677 & 169.65 & $* * *$ & 0.731 & 182.42 & $* * *$ \\
\hline $\begin{array}{l}\text { Price of residence } \\
\text { (log, } 6 \text { digit postal code) }\end{array}$ & & & & -1.144 & -189.31 & $* * *$ & -1.123 & -185.82 & $* * *$ \\
\hline $\begin{array}{r}\text { Size of residence } \\
\text { (log, } 6 \text { digit postal code) }\end{array}$ & & & & 0.328 & 32.49 & $* * *$ & 0.257 & 25.53 & $* * *$ \\
\hline $\begin{array}{r}\text { Rate of price appreciation } \\
\text { of residence }\end{array}$ & & & & & & & & & \\
\hline (2 digit postal sector) & & & & -3.799 & -36.88 & $* * *$ & -2.637 & -25.29 & $* * *$ \\
\hline Income (log) & & & & 0.317 & 125.83 & $* * *$ & 0.206 & 89.17 & $* * *$ \\
\hline Age & & & & & & & 0.004 & 20.15 & $* * *$ \\
\hline Female & & & & & & & -1.410 & -258.87 & $* * *$ \\
\hline Married & & & & & & & 0.117 & 29.78 & $* * *$ \\
\hline Constant & 1.712 & 526.43 & $* * *$ & 12.863 & 186.49 & $* * *$ & 13.903 & 205.21 & $* * *$ \\
\hline Number of observations & 34,117 & & & 34,117 & & & 34,117 & & \\
\hline Number of individuals & 5,258 & & & 5,258 & & & 5,258 & & \\
\hline
\end{tabular}

Notes: Table 5 summarizes the results of quarterly regressions (Panel-GLM with log link) that examine the relationship between residential circles (condo vs. HDB) and indebtedness using the matched sample. The 
dependent variable is the quarterly average of monthly credit card debt balance in Panel A and the quarterly average of monthly credit card debt under delinquency for 30-210 days in Panel B. The main independent variable is the condo dummy variable that takes the value of 1 if individuals are condo residents and 0 if they are HDB residents. Model 1 includes only the condo dummy and the constant term. Model 2 adds proxies for wealth and permanent income. Model 3 also adds the demographic controls. *** indicates significance at the $1 \%$ level, ** indicates significance at the $5 \%$ level, and * indicates significance at the $10 \%$ level. 
Table 6 Conspicuous consumption and credit card indebtedness

Panel A: Total credit card debt

\begin{tabular}{|c|c|c|c|}
\hline \multirow[t]{2}{*}{ Dependent variable: } & \multicolumn{3}{|c|}{ Credit card debt } \\
\hline & $B$ & $z$ & \\
\hline Conspicuous consumption & -0.095 & -37.69 & $* * *$ \\
\hline Condo & 0.090 & 205.55 & $* * *$ \\
\hline Condo x Conspicuous consumption & 0.423 & 121.00 & $* * *$ \\
\hline Constant \& Controls & included & & \\
\hline Number of observations & 27,770 & & \\
\hline Number of individuals & 4,928 & & \\
\hline
\end{tabular}

Panel B: Delinquent credit card debt

\begin{tabular}{|c|c|c|c|}
\hline \multirow[t]{2}{*}{ Dependent variable: } & \multicolumn{3}{|c|}{ Delinquent credit card debt } \\
\hline & $B$ & $z$ & \\
\hline Conspicuous consumption & -2.641 & -48.61 & $* * *$ \\
\hline Condo & 0.851 & 196.66 & $* * *$ \\
\hline Condo x Conspicuous consumption & 0.982 & 15.13 & $* * *$ \\
\hline Constant \& Controls & included & & \\
\hline Number of observations & 27,770 & & \\
\hline Number of individuals & 4,928 & & \\
\hline
\end{tabular}

Notes: Table 6 summarizes the result of quarterly regressions (Panel-GLM with log link) that examine the relationship between conspicuous consumption and indebtedness interacted with the residential circles (condo vs. HDB) using the matched sample. The dependent variable is credit card debt balance in Panel A and credit card debt under delinquency for 30-210 days in Panel B. Conspicuous consumption is the lagged quarterly average of the fraction of monthly card spending at the top 10\% conspicuous stores based on Heffetz (2011) out of the total monthly card spending. The condo dummy variable takes the value of 1 if individuals are condo residents and 0 if they are HDB residents. Our main focus is the interaction between the condo dummy and conspicuous consumption. *** indicates significance at the $1 \%$ level, ** indicates significance at the $5 \%$ level, and $*$ indicates significance at the $10 \%$ level. 
Table 7 Heterogeneity of conspicuous consumption and indebtedness

Panel A: Age

\begin{tabular}{|c|c|c|c|c|c|c|}
\hline \multirow[t]{3}{*}{ Dependent variable: } & \multicolumn{3}{|c|}{ Conspicuous } & \multirow{2}{*}{\multicolumn{3}{|c|}{ Credit Card Debt }} \\
\hline & \multicolumn{3}{|c|}{ Consumption } & & & \\
\hline & $B$ & $z$ & & $B$ & $z$ & \\
\hline Age & -0.451 & -2.64 & $* *$ & 0.793 & 603.58 & $* * *$ \\
\hline Condo & 0.417 & 11.70 & $* * *$ & 1.489 & 217.96 & $* * *$ \\
\hline Condo x Age & -0.150 & -0.63 & & -0.380 & -208.02 & $* * *$ \\
\hline Constant \& Controls & included & & & included & & \\
\hline
\end{tabular}

Panel C: Marital status

\begin{tabular}{|c|c|c|c|c|c|}
\hline \multirow[t]{3}{*}{ Dependent variable: } & \multicolumn{2}{|c|}{ Conspicuous } & \multirow{2}{*}{\multicolumn{3}{|c|}{ Credit Card Debt }} \\
\hline & \multicolumn{2}{|c|}{ Consumption } & & & \\
\hline & $B$ & $z$ & $B$ & $z$ & \\
\hline Married & 0.113 & 1.37 & -0.042 & -68.73 & $* * *$ \\
\hline Condo & 0.245 & $3.14 * * *$ & 0.117 & 195.88 & $* * *$ \\
\hline Condo x Married & -0.038 & 0.35 & -0.089 & -105.91 & $* * *$ \\
\hline Constant \& Controls & included & & included & & \\
\hline
\end{tabular}

\section{Panel B: Gender}

\begin{tabular}{|c|c|c|c|c|c|}
\hline \multirow[t]{3}{*}{ Dependent variable: } & \multicolumn{3}{|c|}{ Conspicuous } & \multirow{2}{*}{\multicolumn{2}{|c|}{ Credit Card Debt }} \\
\hline & \multicolumn{3}{|c|}{ Consumption } & & \\
\hline & $B$ & $z$ & & $B$ & \\
\hline Female & -0.061 & -0.73 & & $-0.244-376.69$ & $* * *$ \\
\hline Condo & 0.314 & 4.58 & $* * *$ & 289.66 & *** \\
\hline Condo x Female & -0.239 & -2.14 & $* *$ & $-0.237-263.03$ & $* * *$ \\
\hline
\end{tabular}

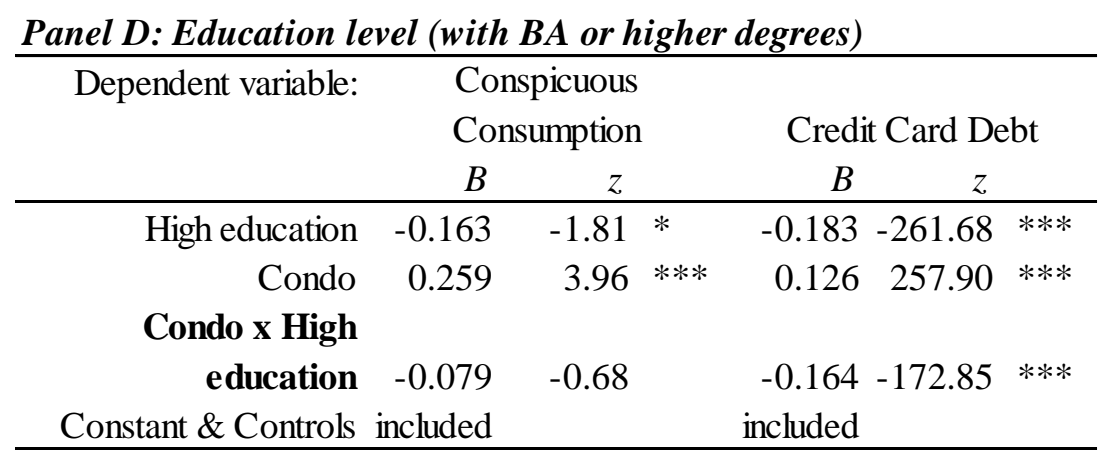

Notes: Table 7 summarizes the results of quarterly regressions (Panel-GLM with log link) that examine the heterogeneity of the relationship between the residential circles and conspicuous consumption and indebtedness using the matched sample (5,258 individuals). In the conspicuous consumption model, the dependent variable is the quarterly average of the fraction of monthly card spending at the top 10\% conspicuous stores based on Heffetz (2011) out of the total monthly card spending. In the credit card debt model, the dependent variable is the quarterly average of monthly credit card debt balance. The condo dummy variable takes the value of 1 if individuals are condo residents and 0 if they are HDB residents. The female variable in Panel B takes the value of 1 if individuals are female and 0 otherwise. The married variable in Panel $\mathrm{C}$ takes the value of 1 if individuals are married and 0 otherwise. In Panel $\mathrm{D}$, the high education variable takes the value of 1 if individuals have a Bachelor's or higher degrees and 0 otherwise. All of the same control variables (except for variables used to test heterogeneous effects, e.g., age in Panel A) are included in the regressions. *** indicates significance at the $1 \%$ level, ** indicates significance at the 5\% level, and $*$ indicates significance at the $10 \%$ level. 


\section{Figure 1 Quality of propensity score matching sample}
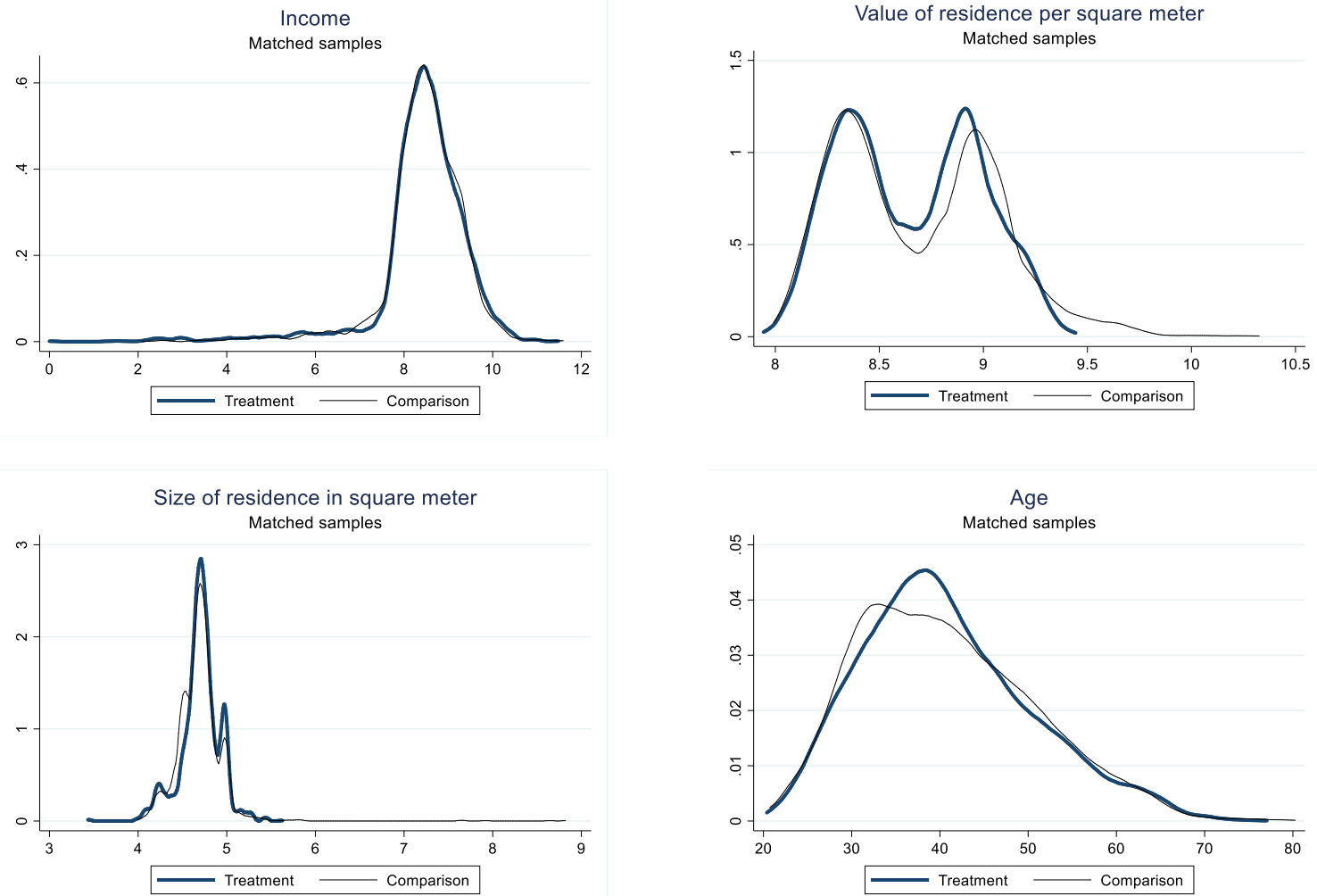

Notes: Figure 1 shows the treatment group (condo residents) and the comparison group (HDB residents) comparison of distributions (QQ plots) of monthly income (log), value of residence per square meter $(\log )$, size of residence in square meter $(\log )$, and age, after the matching process. 


\section{Appendix A-1: Definition of conspicuous stores}

We define the merchant categories that are likely to sell visible goods based on Heffetz (2011) and Charles, Hurst and Roussanov (2009) (hereafter CHR) as potential conspicuous stores.

By conducting anonymous online survey of 320 students at the University of Chicago's Harris School and Graduate School of Business, CHR (2009) define "visible goods" as: expenditures on apparel (including accessories such as jewelry), personal care, and vehicles (excluding maintenance). Similarly, Heffetz (2011) uses a randomized survey among a sample from the population over age 18 in the continental United States. Based on 480 completed interviews, a "visibility index" (hereafter VI) is created for all the 31 categories of goods included in the paper. The VI varies from 0 to 1 , and a higher value means higher perceived visibility from the interviewees. We compare the measures from two papers and find that all categories of "visible goods" defined in CHR (2009) have a higher VI than the 0.6 in Heffetz (2011).

Specifically, there are 10 categories of goods out of 31 categories in Heffetz (2011) that have $\mathrm{VI} \geq 0.6$, including cigarettes ( $\mathrm{VI}=0.76$ ), cars $(\mathrm{VI}=0.73$ ), clothing $(\mathrm{VI}=0.71)$, furniture $(\mathrm{VI}=0.68)$, jewelry $(\mathrm{VI}=0.67)$, recreation $1(\mathrm{VI}=0.66)$, food out $(\mathrm{VI}=0.62)$, alcohol home $(\mathrm{VI}=0.61)$, barbers, etc. $(\mathrm{VI}=0.60)$, and alcohol out $(\mathrm{VI}=0.60)$. There is another category of recreation goods in Heffetz (2011) - "recreation 2" - with a VI of 0.58, which ranks next to "barbers, etc." and "alcohol out". Because the merchant categories in our card transaction data do not cleanly distinguish between the two types of recreational activities/goods, we classify all goods/services in "recreation 1" and "recreation 2" defined in Heffetz (2011), together with the other 9 categories of goods that with $\mathrm{VI} \geq 0.6$ are defined as "visible goods".

We report how we relate the merchant categories in the card transaction data to the visible goods' categories defined in CHR (2009) and Heffetz (2011) in Table A1 below. Note that if any categories of goods among the above-mentioned 11 categories in Heffetz (2011) are not reported in Table A1, it means that there is no corresponding merchant category in our card transaction data.

For our measurement of conspicuous consumption, we start with all local stores (excluding auction houses) in our dataset that fall into the categories defined in Heffetz (2011) or CHR (2009). Then, we rank these stores by per-transaction amount spent by all individuals in our initial sample. For our main analyses, we define the top 10\% stores based on Heffetz (2011) as conspicuous stores. For robustness checks, we use the top 20\% stores based on Heffetz (2011) as well as the top 10\% and 20\% stores based on CHR (2009). The stores in the categories defined in CHR (2009) tend to sell goods that are both visible and portable.

[Insert Table A1 about Here] 


\section{Table A1 Merchant categories of conspicuous stores in credit card transaction data}

\begin{tabular}{|c|c|c|c|c|}
\hline $\begin{array}{l}\text { Category Name in Credit } \\
\text { Card Transaction Data }\end{array}$ & $\begin{array}{l}\text { Category Name in } \\
\text { CHR (2009) }\end{array}$ & $\begin{array}{c}\text { Visibl } \\
\text { e } \\
\text { Goods } \\
\text { in } \\
\text { CHR } \\
(2009) \\
(3)\end{array}$ & $\begin{array}{l}\text { Category Name } \\
\text { in Heffetz (2011) }\end{array}$ & $\begin{array}{l}\text { Visibility } \\
\text { Index } \\
\text { in Heffetz } \\
(2011) \\
(5)\end{array}$ \\
\hline specialty retail & Clothing/jewelry & Yes & $\begin{array}{c}\text { Cigarettes/jewelry/alcohol } \\
\text { home }\end{array}$ & $\begin{array}{c}0.76 / 0.67 / 0.6 \\
1\end{array}$ \\
\hline automotive related & $\begin{array}{l}\text { Vehicle } \\
\text { (expanded) }\end{array}$ & Yes & Cars & 0.73 \\
\hline rental & $\begin{array}{l}\text { Vehicle } \\
\text { (expanded) }\end{array}$ & Yes & Cars & 0.73 \\
\hline apparel & Clothing/jewelry & Yes & Clothing & 0.71 \\
\hline departmental stores & Clothing/jewelry & Yes & Clothing & 0.71 \\
\hline watches \& jewelry & Clothing/jewelry & Yes & Clothing & 0.71 \\
\hline $\begin{array}{l}\text { home/office furnishing \& } \\
\text { appliances }\end{array}$ & & No & Furniture & 0.68 \\
\hline electronic and computer & & No & Recreation 1 & 0.66 \\
\hline music & & No & Recreation 1 & 0.66 \\
\hline entertainment \& recreational & & No & Recreation 1 / recreation 2 & $0.66 / 0.58$ \\
\hline dining & & No & Food out/alcohol out & $0.62 / 0.60$ \\
\hline associations/memberships & Personal care & Yes & Barbers, etc./ recreation 2 & $0.60 / 0.58$ \\
\hline pets & & No & Recreation 2 & 0.58 \\
\hline
\end{tabular}

Note. This table presents the merchant categories used to define conspicuous stores. If any categories of goods among the 11 categories with $\mathrm{VI} \geq 0.58$ in Heffetz (2011) are not reported here, it means that there is no corresponding merchant category in our data. 


\section{Appendix A-2: Summary statistics of conspicuous stores}

\begin{tabular}{lrr}
\hline Number of conspicuous stores & 4,895 \\
Total number of stores in the categories defined in Heffetz (2011) & 48,953 \\
Per-transaction amount & \\
& Mean & $\$ 2,010.97$ \\
& Std. Dev. & $\$ 7,494.46$ \\
Min. & $\$ 667.50$ \\
Max. & $\$ 435,981.50$ \\
\hline
\end{tabular}

Notes: This table summarizes the statistics on transactions at 4,895 conspicuous stores, which are ranked as the top $10 \%$ stores in terms of per-transaction amount among all local stores in the categories defined in Heffetz (2011) in our dataset. Statistics are based on the entire sample of 187,249 individuals for the complete sample period between April 2010 and March 2012. 


\section{Appendix A-3: Examples of stores defined as "conspicuous stores": Rank 1-50}

\begin{tabular}{|c|c|c|}
\hline Rank Merchant name & Merchant category & $\begin{array}{l}\text { Average per-transaction } \\
\text { amount (Singapore Dollar) }\end{array}$ \\
\hline 1 ROLEX & Specialty Retail & 435,982 \\
\hline 2 MALAYAN MOTOR & Automotive Related & 155,241 \\
\hline 3 KING FOOK JEW GROUP & Watches \& Jewelry & 100,289 \\
\hline 4 RICHARD MILLE & Watches \& Jewelry & 96,000 \\
\hline 5 SWISS WATCH GALLERY & Specialty Retail & 84,680 \\
\hline 6 RICHARD MILLE SINGAPORE & Watches \& Jewelry & 81,098 \\
\hline 7 BULGARI & Department Stores & 53,898 \\
\hline 8 PATEK PHILIPPE MBS & Watches \& Jewelry & 50,950 \\
\hline 9 ITAL AUTO SING & Automotive Related & 50,660 \\
\hline 10 IWC 1881 HERITAGE & Department Stores & 41,333 \\
\hline 11 ART SEASON & Watches \& Jewelry & 40,000 \\
\hline 12 BJ ARTRIVIUM ART COMMU & Department Stores & 33,100 \\
\hline 13 JEWEL BY SARA & Watches \& Jewelry & 31,000 \\
\hline 14 DEGEM & Watches \& Jewelry & 29,000 \\
\hline 15 WATABE & Personal Services & 28,859 \\
\hline 16 GEORG LANG SEL ERBEN & Specialty Retail & 24,766 \\
\hline 17 KENSOON ASIATIC ART & Specialty Retail & 23,800 \\
\hline 18 HARRY WINSTON SINGAPORE & Watches \& Jewelry & 21,667 \\
\hline 19 OMEGA BOUTIQUE & Watches \& Jewelry & 20,750 \\
\hline 20 HUBLOT BOUTIQUE-MBS & Watches \& Jewelry & 20,270 \\
\hline 21 LOTTO CARPET GALLERY & Home/Office Furnishing \& Appliances & 19,935 \\
\hline 22 ITAL AUTO & Automotive Related & 18,913 \\
\hline 23 MU-DIAN & Home/Office Furnishing \& Appliances & 17,655 \\
\hline 24 AAKAAR EXQUISITES & Specialty Retail & 16,901 \\
\hline 25 SWISS WATCH GALLERY SI & Watches \& Jewelry & 16,819 \\
\hline 26 KWOK GALLERY & Specialty Retail & 16,000 \\
\hline 27 LOANG \& NOI SI & Watches \& Jewelry & 16,000 \\
\hline 28 CREAM & Home/Office Furnishing \& Appliances & 15,511 \\
\hline 29 SIANG HOA Jewelry & Watches \& Jewelry & 15,000 \\
\hline 30 GUBELIN LUZERN & Watches \& Jewelry & 14,490 \\
\hline 31 ART SEASON SI & Specialty Retail & 14,400 \\
\hline 32 AL MULLA Jewelry & Watches \& Jewelry & 13,349 \\
\hline 33 EMPEROR WATCH \& JEW 97 & Watches \& Jewelry & 12,836 \\
\hline 34 LAGUNA-GUEST ROOM & Entertainment \& Recreational & 11,908 \\
\hline 35 MOIE & Home/Office Furnishing \& Appliances & 11,712 \\
\hline 36 RWS CMS & Entertainment \& Recreational & 11,630 \\
\hline 37 CHLOE 3862 & Watches \& Jewelry & 11,600 \\
\hline 38 SOO KEE LUXURY & Watches \& Jewelry & 11,500 \\
\hline 39 BOUTIQUE BREGUET & Watches \& Jewelry & 11,315 \\
\hline 40 SINCERE HAUTE HORLOGER & Watches \& Jewelry & 11,251 \\
\hline 41 BULGARI ASIA PACIFIC CENTRAL & Watches \& Jewelry & 11,216 \\
\hline 42 LIGNE ROSET & Home/Office Furnishing \& Appliances & 11,183 \\
\hline 43 AUDI CAR SALES & Automotive Related & 11,147 \\
\hline 44 ZIGERLI + IFF & Watches \& Jewelry & 11,099 \\
\hline 45 THE ATTIC PLACE SINGAPORE & Apparel & 10,833 \\
\hline 46 LOANG \& NOI-PARAGON & Watches \& Jewelry & 10,733 \\
\hline 47 ROLF BENZ & Home/Office Furnishing \& Appliances & 10,667 \\
\hline 48 E'COLLEZIONE & Watches \& Jewelry & 10,600 \\
\hline 49 SALAM CARPET & Home/Office Furnishing \& Appliances & 10,500 \\
\hline 50 MALAYAN MOTOR & Automotive Related & 10,453 \\
\hline
\end{tabular}

Notes: This table lists the top 50 conspicuous stores (1-50 ranked by the average per-transaction amount spent) in our dataset based on Heffetz (2011). 


\section{Appendix A-4: Examples of stores defined as "conspicuous stores": Rank 4846-4895}

\begin{tabular}{|c|c|c|}
\hline Rank Merchant name & Merchant category & $\begin{array}{l}\text { Average per-transaction } \\
\text { amount (Singapore Dollar) }\end{array}$ \\
\hline 4846 STUART WEITZMAN & Apparel & 672 \\
\hline 4847 LIN KONG WATCH & Watches \& Jewelry & 672 \\
\hline 4848 THE MONTELLA DESIGN-IM & Home/Office Furnishing \& Appliances & 672 \\
\hline 4849 ONE DRESS/ TAP & Apparel & 672 \\
\hline 4850 K SUITES@ OPH & Dining & 672 \\
\hline 4851 SAVELINK CONNECTION-TR & Home/Office Furnishing \& Appliances & 672 \\
\hline 4852 BOSSIN HAIR CARE \& BEA & Personal Services & 672 \\
\hline 4853 SUNDAN SUN DEPARTMENT & Department Stores & 672 \\
\hline 4854 ST DAVID \& NORFOLK & Dining & 672 \\
\hline 4855 PRAISE BEAUTY \& SLIMMI & Personal Services & 672 \\
\hline 4856 D'LOOKZ THE REVIVAL & Personal Services & 672 \\
\hline 4857 FLYING DRAGON ADVENTURE & Entertainment \& Recreational & 671 \\
\hline 4858 DE LAMAI & Dining & 671 \\
\hline 4859 KALLANG SELF STORAGE & Specialty Retail & 671 \\
\hline 4860 CYBER CAR SERVICE & Automotive Related & 671 \\
\hline 4861 HONG TYRE-274 BRADDELL & Automotive Related & 671 \\
\hline 4862 DERMA FLORA BEAUTY & Personal Services & 671 \\
\hline 4863 MERLIN BEACH RESORT & Dining & 671 \\
\hline 4864 STAMFORD CATERING & Dining & 671 \\
\hline 4865 QUAYSIDE SEAFOOD SIN & Dining & 670 \\
\hline 4866 JANE ART \& CRAFT SIN & Specialty Retail & 670 \\
\hline $4867 \mathrm{BOSCH}$ & Electronic and Computer & 670 \\
\hline 4868 KEMPINSKI HOTEL & Dining & 670 \\
\hline 4869 ITC SONAR FRONT OFFICE & Dining & 670 \\
\hline 4870 THE MANDARIN COMPANY & Apparel & 669 \\
\hline 4871 WEE HENG AUTO SUPPLY-E & Automotive Related & 669 \\
\hline 4872 DREAMZ KABUKI & Dining & 669 \\
\hline 4873 BAN NEE CHEN ENTERPRISE & Specialty Retail & 669 \\
\hline 4874 DANIEL EDWARD & Personal Services & 669 \\
\hline 4875 01EASE COX INTERNATIONAL & Personal Services & 669 \\
\hline 4876 SUNWAY PUTRA HOTEL -M & Dining & 669 \\
\hline 4877 TILO ROSSMANITH & Electronic and Computer & 669 \\
\hline 4878 L \& B BEAUTY HOUSE & Personal Services & 669 \\
\hline 4879 BEI CHEN SHIYE-GONGYU & Dining & 669 \\
\hline 4880 TAJ MAHAL HOTEL FOC & Dining & 669 \\
\hline 4881 SWING KING ACADEMIES & Entertainment \& Recreational & 669 \\
\hline 4882 GRACE HOTEL & Dining & 669 \\
\hline 4883 02FRANCES BEAUTY CLINIC & Personal Services & 669 \\
\hline 4884 05GLOWER HAIR CARE-06M & Personal Services & 669 \\
\hline 4885 MEDICAL AESTHETIC SPA & Personal Services & 669 \\
\hline 4886 PARKNASILLA HOTEL & Dining & 668 \\
\hline 4887 LARGOS HOTEL & Dining & 668 \\
\hline 4888 FM SKINCARE & Personal Services & 668 \\
\hline 4889 ST REGIS & Dining & 668 \\
\hline 4890 EDISON ELECT IND & Electronic and Computer & 668 \\
\hline 4891 TX SONGBIAO SILK CO & Home/Office Furnishing \& Appliances & 668 \\
\hline 4892 MAX MARA-MBS & Apparel & 668 \\
\hline 4893 LE ARTICLE & Home/Office Furnishing \& Appliances & 668 \\
\hline 4894 BALLY & Apparel & 668 \\
\hline 4895 BLISSLITE GALLERY & Home/Office Furnishing \& Appliances & 668 \\
\hline
\end{tabular}


Notes: This table lists the bottom 50 stores (4846-4895 ranked by the average per-transaction amount spent) in our dataset based on Heffetz (2011). 


\section{Appendix B: Robustness checks with alternative conspicuous consumption measures}

\section{Residential circles and alternative conspicuous consumption measures}

\begin{tabular}{|c|c|c|c|c|c|c|c|c|c|c|c|c|}
\hline \multirow[t]{2}{*}{ Dependent variable: } & \multicolumn{3}{|c|}{$\begin{array}{c}\text { Panel A: } \\
\text { Hefffetz (2011), Top 10\% }\end{array}$} & \multicolumn{3}{|c|}{$\begin{array}{c}\text { Panel B: } \\
\text { Hefffetz (2011), Top 20\% }\end{array}$} & \multicolumn{3}{|c|}{$\begin{array}{c}\text { Panel C: } \\
\text { CHR (2009), Top } 10 \%\end{array}$} & \multicolumn{3}{|c|}{$\begin{array}{c}\text { Panel D: } \\
\text { CHR (2009), Top 20\% }\end{array}$} \\
\hline & $B$ & $z$ & & $B$ & $z$ & & $B$ & $z$ & & $B$ & $z$ & \\
\hline Condo & 0.225 & 4.15 & $* * *$ & 0.157 & 4.20 & $* * *$ & 0.175 & 2.06 & $* *$ & 0.152 & 2.70 & $* * *$ \\
\hline $\begin{array}{r}\text { Price of residence } \\
\text { (log, } 6 \text { digit postal code) }\end{array}$ & -0.003 & -0.05 & & -0.089 & -1.68 & $*$ & 0.006 & 0.05 & & -0.065 & -0.82 & \\
\hline $\begin{array}{r}\text { Size of residence } \\
(\log , 6 \text { digit postal code })\end{array}$ & -0.062 & -0.44 & & 0.000 & 0.00 & & 0.070 & 0.32 & & 0.048 & 0.32 & \\
\hline $\begin{array}{r}\text { Rate of price appreciation } \\
\text { of residence } \\
\text { (2 digit postal sector) }\end{array}$ & -0.607 & -0.41 & & -0.930 & -0.90 & & -0.330 & -0.14 & & -0.270 & -0.17 & \\
\hline Income (log) & 0.081 & 2.67 & $* * *$ & 0.040 & 1.97 & $* *$ & 0.190 & 3.65 & $* * *$ & 0.070 & 2.25 & $* *$ \\
\hline Age & -0.014 & -4.47 & $* * *$ & 0.001 & 0.43 & & -0.010 & -2.14 & $* *$ & 0.004 & 1.40 & \\
\hline Female & -0.194 & -3.45 & $* * *$ & -0.216 & 5.52 & $* * *$ & -0.272 & -3.04 & $* * *$ & -0.272 & -4.56 & $* * *$ \\
\hline Married & 0.092 & 1.63 & $*$ & -0.015 & -0.39 & & 0.104 & 1.18 & & 0.066 & 1.14 & \\
\hline Constant & -3.036 & -3.47 & $* * *$ & -1.590 & -2.63 & $* * *$ & -5.721 & -4.25 & $* * *$ & -3.405 & -3.77 & $* * *$ \\
\hline Number of observations & 34,117 & & & 34,117 & & & 34,117 & & & 34,117 & & \\
\hline Number of individuals & 5,258 & & & 5,258 & & & 5,258 & & & 5,258 & & \\
\hline
\end{tabular}

Notes: This table summarizes the results of robustness checks with alternative conspicuous consumption measures. It shows the results of quarterly regressions (Panel-GLM with log link) that examine the relationship between residential circles (condo vs. HDB) and conspicuous consumption using the matched sample. In Panel A, the dependent variable is our main conspicuous consumption measure, the quarterly average of the fraction of monthly card spending at the top $10 \%$ conspicuous stores based on Heffetz (2011) out of the total monthly card spending, so the result is same as the one shown in Table 3. In Panel B, the dependent variable is the quarterly average of the fraction of monthly card spending at the top $20 \%$ conspicuous stores based on Heffetz (2011) out of the total monthly card spending. As shown in Table A1, the categories defined in CHR (2009) are more limited and the stores in the categories are more likely to sell visible and portable goods. In Panel C and D, the dependent variable is the quarterly average of the fraction of the monthly card spending at the top $10 \%$ and $20 \%$

conspicuous stores based on CHR (2009) out of the total monthly card spending, respectively. The condo dummy variable takes the value of 1 if individuals are condo residents and 0 if they are HDB residents. $* * *$ indicates significance at the $1 \%$ level, ** indicates significance at the $5 \%$ level, and $*$ indicates significance at the $10 \%$ level. 


\section{Appendix C: Robustness checks with different matched samples}

Panel A: Only Singaporeans Dependent variable:

Conspicuous

Consumption

\begin{tabular}{|c|c|c|c|c|c|}
\hline & $B$ & $z$ & $B$ & $z$ & \\
\hline Condo & 0.190 & $3.26 * * *$ & 0.103 & 18.26 & $* * *$ \\
\hline Constant \& Controls & included & & included & & \\
\hline Number of observations & 33,095 & & & & \\
\hline Number of individuals in & & & & & \\
\hline Treatment: Condo & 2,501 & & & & \\
\hline Comparison: HDB & 2,501 & & & & \\
\hline
\end{tabular}

Panel C: Only individuals with Bachelor's degree

\begin{tabular}{|c|c|c|c|}
\hline \multirow[t]{3}{*}{ Dependent variable: } & \multicolumn{2}{|c|}{ Conspicuous } & \multirow[b]{2}{*}{ Credit Card Debt } \\
\hline & \multicolumn{2}{|c|}{ Consumption } & \\
\hline & $B$ & $z$ & $B \quad z$ \\
\hline Condo & 0.167 & $1.95 * *$ & 0.148198 .28 *** \\
\hline Constant \& Controls & included & & included \\
\hline Number of observations & 15,004 & & \\
\hline Number of individuals in & & & \\
\hline Treatment: Condo & 1,182 & & \\
\hline Comparison: $\mathrm{HDB}$ & 1,182 & & \\
\hline
\end{tabular}

Panel E: No matching

Dependent variable:

\begin{tabular}{|c|c|c|c|}
\hline \multirow[t]{3}{*}{ Dependent variable: } & \multicolumn{2}{|c|}{ Conspicuous } & \multirow[b]{2}{*}{ Credit Card Debt } \\
\hline & \multicolumn{2}{|c|}{ Consumption } & \\
\hline & $B$ & $z$ & $B$ \\
\hline Condo & 0.092 & $3.25 * * *$ & 0.125560 .53 **: \\
\hline Constant \& Controls & included & & included \\
\hline Number of observations & 773,072 & & \\
\hline Number of individuals in & & & \\
\hline Treatment: Condo & 16,081 & & \\
\hline Comparison: $\mathrm{HDB}$ & 106,450 & & \\
\hline
\end{tabular}

Panel B: Same neighborhood

\begin{tabular}{|c|c|c|c|}
\hline \multirow[t]{3}{*}{ Dependent variable: } & \multicolumn{3}{|c|}{ Conspicuous } \\
\hline & \multicolumn{2}{|c|}{ Consumption } & Credit Card Debt \\
\hline & $B$ & $z$ & $B \quad z$ \\
\hline Condo & 0.304 & $3.61 * * *$ & $0.059200 .14 * * *$ \\
\hline Constant \& Controls & included & & included \\
\hline Number of observations & 14,011 & & \\
\hline \multicolumn{4}{|l|}{ Number of individuals in } \\
\hline Treatment: Condo & 1,081 & & \\
\hline Comparison: HDB & 1,081 & & \\
\hline \multicolumn{4}{|l|}{ anel D: No caliper } \\
\hline \multirow[t]{3}{*}{ Dependent variable: } & \multicolumn{2}{|c|}{ Conspicuous } & \multirow[b]{2}{*}{ Credit Card Debt } \\
\hline & \multicolumn{2}{|c|}{ Consumption } & \\
\hline & $B$ & $z$ & $B \quad z$ \\
\hline Condo & 0.180 & $8.23 * * *$ & $0.058206 .79 * * *$ \\
\hline Constant \& Controls & included & & included \\
\hline Number of observations & 212,562 & & \\
\hline Number of individuals in & & & \\
\hline Treatment: Condo & 16,055 & & \\
\hline Comparison: HDB & 16,055 & & \\
\hline
\end{tabular}


Notes: This table summarizes the results of quarterly regressions (Panel-GLM with log link) for robustness checks with different matched samples created using different criteria. In the conspicuous consumption model, the dependent variable is the quarterly average of the fraction of monthly card spending at the top $10 \%$ conspicuous stores based on Heffetz (2011) out of the total monthly card spending. In the credit card debt model, the dependent variable is the quarterly average of monthly credit card debt balance. The condo dummy variable takes the value of 1 if individuals are condo residents and 0 if they are HDB residents. For all regressions, the value of the residence (log), the size of residence $(\log )$, the rate of price appreciation of residence, income (log), age, female, and married

variables are included as control variables. For all matched samples (except for Panel E), we estimate the propensity score by using the logit model, in which the dependent variable is the condo dummy ( 1 for condo residents and 0 for HDB residents) and the independent variables are value of residence per square meter, size of residence in square meter, income decile, age, gender, and marital status. One-to-one matching is done with no replacement, for which each matched pair is forced to be drawn from the same income decile. The matched sample is created only among Singaporeans (Panel A), those reside in the same postal sector (Panel B), individuals whose highest degree is a Bachelor's (Panel C). In Panel D, the matched sample is created without using any caliper (vs. 0.003 for the main analyses) based on the same matching criteria used for the main matched sample. In Panel E, regressions are run with the unmatched sample of 122,531 individuals (16,081 condo residents and 106,450 HDB residents). $* * *$ indicates significance at the $1 \%$ level, $* *$ indicates significance at the 5\% level, and * indicates significance at the $10 \%$ level. 